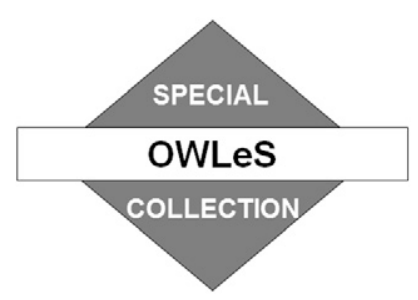

\title{
LLAP Band Structure and Intense Lake-Effect Snowfall Downwind of Lake Ontario: Insights from the OWLeS 7-9 January 2014 Event 0
}

\author{
PHILIP T. BERGMAIER AND BART GEERTS \\ Department of Atmospheric Science, University of Wyoming, Laramie, Wyoming
}

(Manuscript received 12 December 2019, in final form 14 August 2020)

\begin{abstract}
Modeling and observational studies stemming from the 2013-14 Ontario Winter Lake-Effect Systems (OWLeS) field campaign have yielded much insight into the structure and development of long-lake-axis-parallel (LLAP) lake-effect systems over Lake Ontario. This study uses airborne single- and dual-Doppler radar data obtained during two University of Wyoming King Air flights, as well as a high-resolution numerical model simulation, to examine and contrast two distinctly different LLAP band structures observed within a highly persistent lake-effect system on 7-9 January 2014. On 7 January, a very cold air mass accompanied by strong westerly winds and weak capping aloft resulted in a deep, intense LLAP band that produced heavy snowfall well inland. In contrast, weaker winds, weaker surface heat fluxes, and stronger capping aloft resulted in a weaker LLAP band on 9 January. This band was blocked along the downwind shore and produced only light snowfall closer to the shoreline. Although the two structures examined here represent opposite ends of a spectrum of LLAP bands, both cases reveal a well-organized mesoscale secondary circulation composed of two counterrotating horizontal vortices positioned on either side of a narrow updraft within the band. In both cases, this circulation traces back to a shallow, baroclinic land-breeze front originating along a bulge in the lake's southern shoreline. As the band extends downstream and the low-level baroclinity weakens, buoyancy increases within the band—driven in part by cloud latent heating —leading to band intensification and a deeper, stronger, and more symmetric secondary circulation over the lake.
\end{abstract}

KEYWORDS: Lake effects; Mesoscale processes; Snowbands; Aircraft observations; Radars/Radar observations; Numerical analysis/modeling

\section{Introduction}

During the cool season, lake-effect (LE) snowfall is common over and downwind of the Laurentian Great Lakes in North America when cold air masses are advected across the warmer lake surface. The large surface heat and moisture fluxes that result lead to destabilization of the boundary layer (BL) over the lake and the formation of clouds and precipitation. When the prevailing BL flow is oriented along the major axis of an elongated lake such as Lake Ontario, LE precipitation can develop into a long-lake-axis-parallel (LLAP) system (Peace and Sykes 1966; Niziol et al. 1995; Steiger et al. 2013). LLAP systems may consist of intense, well-organized snowbands (i.e., LLAP bands), weaker, disorganized convective cells, or some hybrid of the two (Campbell et al. 2016).

Multiple LLAP systems were documented over and downwind of Lake Ontario during the 2013-14 Ontario Winter Lake-Effect Systems (OWLeS) field campaign (Kristovich et al. 2017). One of these, the intensive observation period $2 b$

Supplemental information related to this paper is available at the Journals Online website: https://doi.org/10.1175/JAMC-D-190288.s1.

Corresponding author: Philip T. Bergmaier, pbergmai@uwyo.edu
(IOP2b) case, produced more than $100 \mathrm{~cm}$ of snowfall in $24 \mathrm{~h}$ over the Tug Hill Plateau (hereinafter Tug Hill) east of the lake on 11 December 2013. Much has been learned about the dynamics and cloud microphysics of LLAP-type LE systems through this one case (Minder et al. 2015; Campbell et al. 2016; Welsh et al. 2016; Steenburgh and Campbell 2017; Bergmaier et al. 2017; Campbell and Steenburgh 2017; Saslo and Greybush 2017; Jensen et al. 2020). In particular, Steenburgh and Campbell (2017) show how large-scale flow, the shoreline geometry of Lake Ontario, and differential surface heating and roughness led to the development of two land-breeze fronts (LBFs) that played a significant role in the upstream origin of the LLAP band, its downstream evolution, and the precipitation maximum over Tug Hill. During the most intense snowfall period, a well-defined, coherent secondary circulation consisting of two counterrotating vortices was observed within the band (Bergmaier et al. 2017). Simulations with a horizontal resolution $\mathrm{O}(1 \mathrm{~km})$ capture this circulation and the resulting precipitation (Bergmaier et al. 2017; Jensen et al. 2020) and indicate that the circulation originated as a LBF along the southern shore. The circulation deepened, strengthened, and became more symmetric downwind as a result of enhanced buoyancy, driven by latent heating ( $\mathrm{LH})$ over a depth of $\sim 3 \mathrm{~km}$ (Bergmaier et al. 2017). 
Another strong, persistent LLAP system was observed over Lake Ontario on 7-9 January 2014. It featured a long duration $(60+\mathrm{h})$ and often intense LLAP band that produced more than $150 \mathrm{~cm}$ of snowfall just north of Tug Hill (Kristovich et al. 2017). The band was at its peak intensity on 7 January when misovortices, driven by the release of horizontal shearing instability (Mulholland et al. 2017), and isolated lightning (Steiger et al. 2018) were observed. This current study presents new airborne radar observations from two University of Wyoming King Air (UWKA) flights of a wellorganized secondary circulation within this long duration LLAP band. The first flight was on 7 January (IOP7) when the winds were strong, the air mass was cold, the band was deep, and the snowfall was intense. The second flight was conducted on 9 January (IOP9), shortly before the band dissipated, when the winds were weaker, the air mass was warmer, the band was shallower, and the snowfall was light. The inland penetration of the band and associated snowfall differed significantly between these two observational periods. The band remained organized as it extended far inland during IOP7, producing heavy snowfall east of the lake, but weakened rapidly as it moved onshore during IOP9, yielding light snowfall close to the shoreline. This study contrasts these two different LLAP band structures.

The primary objective of this study is to characterize and contrast the development and downstream evolution of the band's secondary circulation during the two IOPs using a combination of finescale airborne radar observations and numerical simulations. A secondary objective is to use this case study to highlight the key factors that likely accounted for the marked change in the band's inland penetration and precipitation between IOP7 and IOP9, building on recent studies of inland penetration of LE precipitation (Villani et al. 2017; Veals et al. 2018; Eipper et al. 2018).

The data and methods used in this study are discussed in section 2, and a detailed overview of the 7-9 January event is given in section 3 . Section 4 presents the airborne radar observations and a comparison of these observations with corresponding model cross sections. A model analysis of the mesoscale forcing and inland penetration of the band is given in section 5 . The results of the study are discussed and summarized in sections 6 and 7 , respectively.

\section{Data and methods}

\section{a. Airborne measurements}

A significant portion of this study focuses on airborne radar data from the Wyoming Cloud Radar (WCR) on board the UWKA. The UWKA also carried probes to measure flightlevel wind speed and direction, temperature, air pressure, humidity, and cloud and precipitation size distributions (Wang et al. 2012). The WCR is a highly sensitive, multiantenna pulsed Doppler radar operating at $95-\mathrm{GHz}$ (3-mm wavelength). Three fixed antennas were utilized during OWLeS, with their beams pointing up (near-zenith), down (near-nadir), and down-forward (about $30^{\circ}$ forward of nadir). For each beam, radar reflectivity and Doppler velocity measurements were sampled at $20 \mathrm{~Hz}$ (every $4-5 \mathrm{~m}$ along the flight track) and in range increments of $15 \mathrm{~m}$.
A standard correction was applied to the WCR velocity measurements to account for aircraft motion (Leon and Vali 1998; Damiani and Haimov 2006). Further information regarding final WCR data processing is provided in Bergmaier et al. (2017). Horizontal wind profiles from proximity soundings-obtained during the IOP7 flight at Henderson Harbor, New York, and during the IOP9 flight at Oswego, New York (Fig. 1b; see section 4b)—were used to remove the horizontal wind contribution from the up and down beam Doppler velocities when the beams were not oriented vertically due to aircraft attitude variations. When compared with other nearby soundings retrieved during the event, the uncertainty of this hydrometeor vertical velocity correction along level flight legs was found to be on the order of $0.1 \mathrm{~m} \mathrm{~s}^{-1}$, depending on flight-level turbulence and sounding wind profile representativeness. To obtain an estimate of the WCR air vertical velocity $w$, a representative hydrometeor fall speed must be added to the hydrometeor vertical velocity. This fall speed is estimated from the mean difference between the UWKA gust probe air vertical velocity at flight level and the WCR hydrometeor vertical velocity from the closest available range gates. The mean fall speeds used for IOP7 and IOP9 were $1.0 \mathrm{~m} \mathrm{~s}^{-1}$ and $0.75 \mathrm{~m} \mathrm{~s}^{-1}$, respectively. Further details about the fall speed estimates and their uncertainties are discussed in appendix A.

\section{b. Dual-Doppler synthesis}

Radial velocity measurements from the two downwardpointing WCR beams were used to retrieve the 2D wind field in the vertical plane below the UWKA via an airborne dualDoppler (DD) synthesis technique described by Leon et al. (2006) and Damiani and Haimov (2006). Further adaptations to obtain the along-track horizontal wind component $u_{\text {track }}$ for flight tracks with a strong crosswind (and thus a significant aircraft crabbing angle), which is frequently encountered when traversing LLAP bands, are described in Bergmaier et al. (2017). A further adaptation is made in this study to directly retrieve the horizontal wind component normal to the LLAP band (hereinafter $u_{\text {normal }}$ ). The reason for this is that some flight tracks were not precisely perpendicular to the band, and the main feature of interest is the cross-band secondary circulation. The retrieval of $u_{\text {normal }}$ and its uncertainties are described in appendix B. In the analyses shown below, the values of $u_{\text {normal }}$ are projected onto a Cartesian grid below flight level along relatively straight and level flight legs, with horizontal-by-vertical grid spacings of $90 \times 60 \mathrm{~m}^{2}$.

\section{c. WRF simulation}

An Advanced Research WRF Model (WRF-ARW, version 3.9; Skamarock and Klemp 2008) simulation is used to further examine the environment around Lake Ontario. The simulation includes three nested domains (Fig. 1a) with grid spacings of 12,4 , and $1.33 \mathrm{~km}$. As the analyses in sections 4 and 5 show, a $1.33-\mathrm{km}$ grid spacing for the innermost domain is more than adequate to capture the mesoscale features of interest in this study. Previous LLAP band studies also bear this out (e.g., Steenburgh and Campbell 2017; Bergmaier et al. 2017). Each domain has 72 terrain-following vertical eta $(\eta)$ 

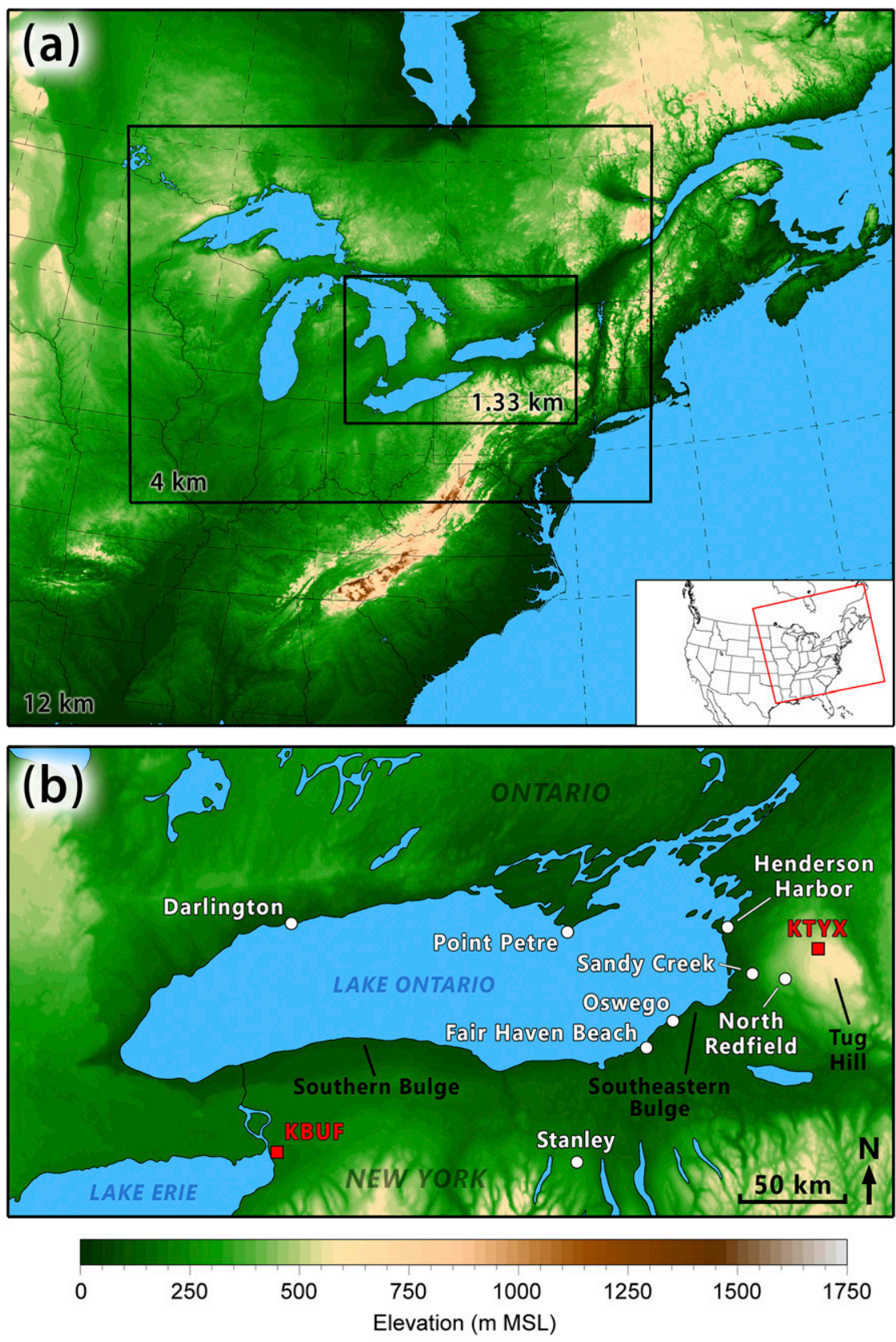

FIG. 1. (a) WRF Model domains, and (b) regional map of Lake Ontario showing relevant locations and geographic features discussed throughout the text.

levels, the first 14 of which are in the lowest $1 \mathrm{~km}$ AGL. Initial and lateral boundary conditions were generated at 6-h intervals with analyses from the 12-km North American Mesoscale Forecast System (NAM). The simulation was run for $96 \mathrm{~h}$, from 0000 UTC 6 January to 0000 UTC 10 January. The model physics configuration includes the Yonsei University planetary boundary layer scheme (Hong et al. 2006), the revised MM5 surface layer scheme (Jiménez et al. 2012), and the Noah land surface model (Chen and Dudhia 2001). The Kain-Fritsch cumulus scheme (Kain and
Fritsch 1990, 1993; Kain 2004) was used for the 12-km domain only, allowing convection to be explicitly resolved in the innermost two domains. For model microphysics, the Predicted Particle Property (P3) microphysics scheme (Morrison and Milbrandt 2015) has been implemented, which is coupled with the Rapid Radiative Transfer Model for GCMs (RRTMG) longwave and shortwave radiation schemes (Iacono et al. 2008). Several other microphysics schemes were tested as well, including Thompson (Thompson et al. 2008), Morrison double-moment (Morrison et al. 2009), 
and Milbrandt-Yau double-moment (Milbrandt and Yau 2005a,b). Each microphysics scheme was tested twice, with either 36 or 72 vertical levels. The 72 -level simulation using the P3 scheme was ultimately chosen, based on a comparison with observed cloud-top heights from the WCR, reflectivity patterns from the WCR and ground-based radars, and thermodynamic and wind profiles from soundings.

Lake Ontario was mostly ice free during the 7-9 January event, except for some of the bays and inlets in its northeastern corner. Ice cover and lake surface temperatures (LSTs) were manually specified for the WRF simulation using gridded surface- and satellite-based analyses valid just prior to the event (6 January) from the Great Lakes Environmental Research Laboratory (GLERL) Great Lakes Coastal Forecasting System (GLCFS). Following Gerbush et al. (2008), areas with $\geq 70 \%$ ice coverage were set as ice in the model and everything else was set as open water.

\section{Event overview}

The long-duration LLAP system examined here occurred during an intrusion of a particularly cold air mass over the eastern Great Lakes beginning on 6 January. Lasting more than $60 \mathrm{~h}$, the event spanned multiple OWLeS IOPs, including IOP7 (2100 UTC 6 January to 2230 UTC 7 January) and IOP9 (0100-1600 UTC 9 January) (Kristovich et al. 2017). From 6 to 8 January, total snowfall accumulations at some locations east of Lake Ontario exceeded $120 \mathrm{~cm}$ (47 in.), with more than $150 \mathrm{~cm}$ (60 in.) in Rodman, New York. Early on in this event, snowfall rates were as high as $9 \mathrm{~cm} \mathrm{~h}^{-1}$ at some locations. On 7 January, ASOS stations east of the lake (e.g., KFZY in Fulton, New York, and KART in Watertown, New York) recorded surface temperatures as low as $-18^{\circ} \mathrm{C}$, with sustained winds of $10-15 \mathrm{~m} \mathrm{~s}^{-1}$ and gusts of up to $20 \mathrm{~m} \mathrm{~s}^{-1}$. Multiple gusts in excess of $27 \mathrm{~m} \mathrm{~s}^{-1}\left(62 \mathrm{mi} \mathrm{h}^{-1}\right)$ were recorded over the lake at Point Petre, Ontario, Canada (see Fig. 1b for location), on 7 January. These intense lake-effect conditions subsided by 9 January.

The synoptic environment was quite favorable for the development of organized LLAP convection over the eastern Great Lakes. A strong 500-hPa trough passed across Lake Ontario between 0400 and 0800 UTC 7 January, lifting the BL capping inversion from 625 to $550 \mathrm{hPa}$ (Mulholland et al. 2017). This trough was accompanied by a deep layer of 20 $30 \mathrm{~m} \mathrm{~s}^{-1}$ westerly flow and $850-\mathrm{hPa}$ temperatures over the lake from $-20^{\circ}$ to $-30^{\circ} \mathrm{C}$ (Figs. 2a,b). With lake surface temperatures of $3^{\circ}-5^{\circ} \mathrm{C}$, lake-to-850-hPa temperature differences were ideal for strong LE convection (Holroyd 1971; Niziol et al. 1995). In fact, the lake-induced CAPE was estimated at about $1300 \mathrm{~J} \mathrm{~kg}^{-1}$ early on 7 January, over a depth of just $2.5 \mathrm{~km}$ (Steiger et al. 2018). Cold, strong westerly flow persisted across Lake Ontario over the next $24-36 \mathrm{~h}$ into early 9 January (not shown). However, an upper-level ridge approaching from the west led to weaker and warmer northwesterly flow over the lake by 1200 UTC 9 January (Figs. 2c,d) and would ultimately herald an end to the LLAP system later that day.

A sequence of level II $0.5^{\circ}$ reflectivity scans from the WSR88Ds in Montague, New York (KTYX), and Buffalo, New York (KBUF), for the 3-day LE event is shown in Fig. 3 (see
Fig. $1 \mathrm{~b}$ for radar locations). ${ }^{1}$ Although the LLAP system initially consisted of multiple disorganized convective features, it quickly evolved into a single, well-organized band over northern Lake Ontario around 0300 UTC 7 January (not shown). By 1200 UTC (Fig. 3a), this band had drifted south over the northern flanks of Tug Hill (see Fig. 1b for location) and strengthened. The band also extended more than $100 \mathrm{~km}$ inland at this time, as far east as the Adirondack Mountains. Near the eastern shore, the band's radar echo tops were persistently between 2.5 and $3.0 \mathrm{~km} \mathrm{MSL}$ (see section 4). A broad region of lighter orographic precipitation was present to the south over Tug Hill (Fig. 3a). The primary band continued to intensify by 0000 UTC 8 January and remained positioned along the northern side of Tug Hill over the course of the next $24 \mathrm{~h}$ (Figs. 3b-d). After weakening slightly by 0000 UTC 9 January (Fig. 3d), the band migrated south of Tug Hill before dissipating by about 1900 UTC (not shown).

The remainder of this paper focuses on the IOP7 and IOP9 UWKA flight periods. The LLAP band structure differed significantly between the two IOPs (Table 1). During IOP7, the band-featuring deeper cloud tops, a stronger main updraft, and more intense precipitation-formed within much colder, stronger flow that generated larger surface heat fluxes over the lake and greater lake-induced thermal instability (i.e., larger lake-to-850-hPa temperature differences). Although the band was much weaker and shallower during IOP9, the precipitable water $(\mathrm{PW})$ values were higher in the warmer environment of IOP9.

\section{WCR analysis and WRF comparison}

\section{a. Overview}

Observational data from two UWKA flights that took place during the event are now examined. The IOP7 flight was from 1312 to 1645 UTC (from 0812 to 1145 LT) 7 January, during one of the more intense periods of LE precipitation when the band was well organized and extended far inland. In fact, KTYX reflectivity was higher $25 \mathrm{~km}$ onshore than $25 \mathrm{~km}$ offshore around this time (Table 1). Five flight legs, ${ }^{2} 25-35 \mathrm{~km}$ in length, were flown across the band from 1338 to 1434 UTC at altitudes of $2.3-2.5 \mathrm{~km}$ MSL (Fig. 4a). As discussed in section $2 \mathrm{~b}$, these legs were flown at a slightly oblique angle to the mean orientation of the band (black dashed line in Fig. 4a). Unfortunately, the legs did not capture the northern margins of the band.

The IOP9 flight took place from 1252 to 1607 UTC (0752 to 1107 LT) 9 January, when the band was positioned farther south and oriented from west-northwest to east-southeast. Seven flight legs, also $25-35 \mathrm{~km}$ in length, were flown across the band from 1320 to 1436 UTC at altitudes of

\footnotetext{
${ }^{1}$ The full 72 -h radar reflectivity animation can be found in the online supplemental material.

${ }^{2}$ Leg 4 from the 7 January flight and leg 3 from the 9 January flight are not included because of missing WCR data along those legs.
} 

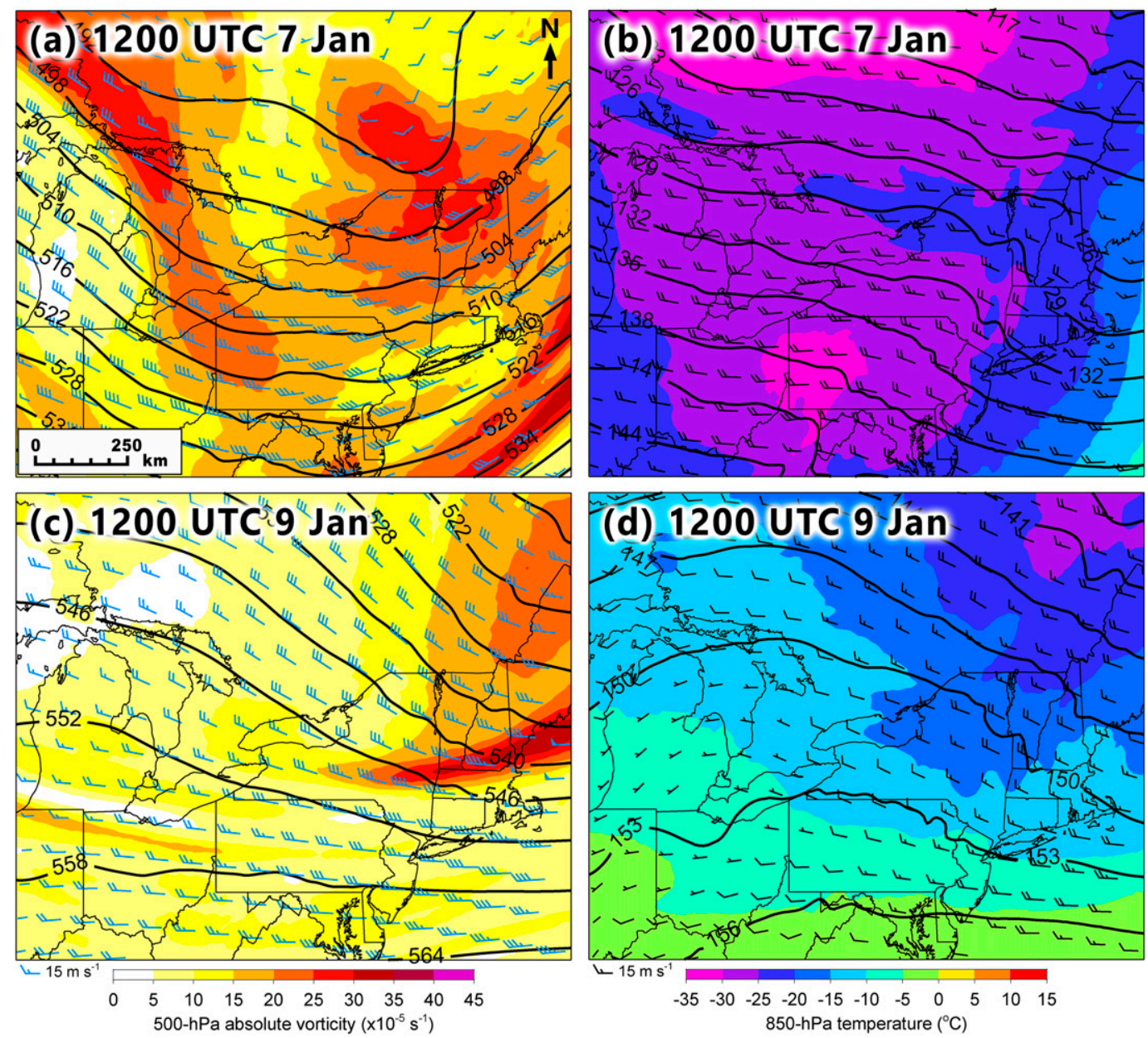

FIG. 2. (left) NAM 500-hPa analysis of absolute vorticity (shaded), geopotential height (black contours every $60 \mathrm{gpm}$ ), and wind (blue barbs) and (right) NAM 850-hPa analysis of temperature (shaded), geopotential height (black contours every $30 \mathrm{gpm}$ ), and wind (black barbs) at $1200 \mathrm{UTC}$ (a),(b) 7 and (c),(d) 9 Jan.

1.3-1.7 km MSL (Fig. 4c). A rough estimate of the band's mean orientation (black dashed line in Fig. 4c) over the eastern half of the lake at 1430 UTC indicates that the UWKA legs were again slightly offset from normal. The band was too shallow at this time to be detected far offshore by the $0.5^{\circ}$ elevation angle scans from KTYX. Maximum cloud tops within the band were typically no higher than $\sim 1.8 \mathrm{~km}$ AGL (note the location of the 1500-m-AGL KTYX beam height contour in Fig. 4c). The band's westward extension over the lake is confirmed with $G O E S-13$ visible satellite imagery and low-level $\left(0.9^{\circ}\right.$ elevation angle $)$ reflectivity scans from a Doppler-on-Wheels radar (DOW7; Wurman et al. 1997) located at Fair Haven Beach, New York (see Fig. 1b for location). Cloud tops were less convective on this day compared to IOP7 (cf. Figs. 4a,c). Additionally, KTYX and DOW7 reflectivity (Fig. 4c) indicate that the band was weaker and did not extend as far inland during this IOP. The mean reflectivity within the band increased slightly from the lake to $\sim 25 \mathrm{~km}$ onshore (Table 1 ), and then dropped off rapidly.

\section{b. General model performance}

The model produces a well-organized, intense LLAP band at 1430 UTC 7 January (Fig. 4b). The location and inland extent of this simulated band tend to agree quite well with the observations, although over land the simulated band location is biased northward by about $20 \mathrm{~km}$ (cf. Figs. 4a,b). Generally, model reflectivity within this band is slightly larger than observed by KTYX. A secondary band is generated by the model just north of the main band, as was observed (also see Fig. 3a). The model-produced cloud field over the lake compares well with visible satellite imagery.

At 1430 UTC 9 January, the model produces a weaker, quasi-linear band that again generally compares well with visible satellite and KTYX reflectivity imagery (Fig. 4d). Simulated reflectivity within the band broadens and weakens onshore, as observed. Over the lake, the horizontal structure of the band is more cellular than on 7 January (cf. Figs. 4b,d). Because of the model's inability to resolve convection smaller than $\sim 5 \mathrm{~km}$ in diameter, the simulated cellular features appear larger than the observed cells (cf. Figs. 4c,d). 

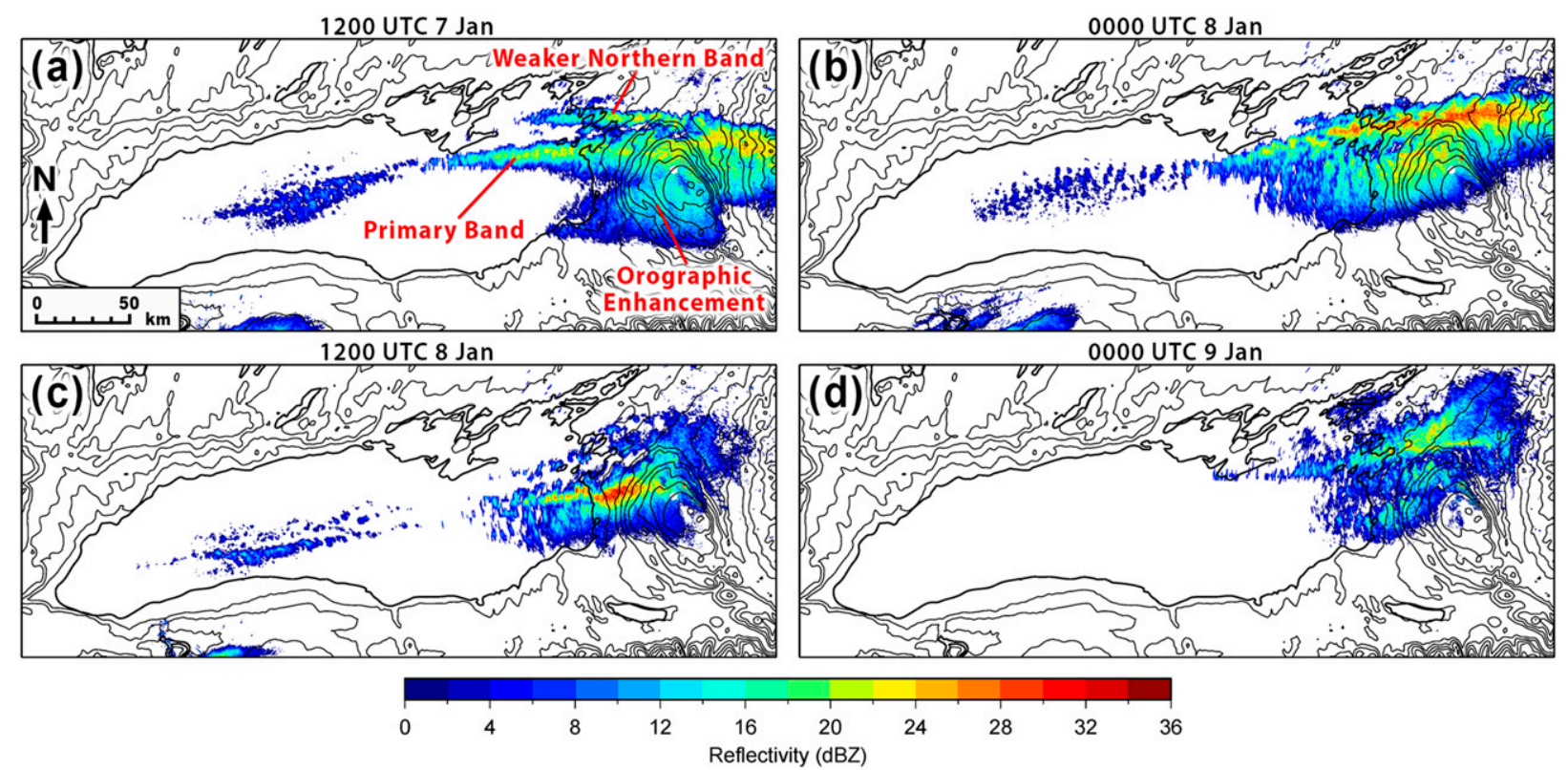

FIG. 3. 12-hourly $0.5^{\circ}$ base reflectivity from KTYX and KBUF at (a) 1200 UTC 7 Jan, (b) 0000 UTC 8 Jan, (c) 1200 UTC 8 Jan, and (d) 0000 UTC 9 Jan. Terrain is contoured in black every $60 \mathrm{~m}$ MSL.

Yet the modeled cells are more narrowly concentrated and organized, suggesting that much of the ascent and precipitation are driven by a solenoidal circulation. As on 7 January, the simulated band is again situated farther north of the observed band by about $10-20 \mathrm{~km}$. However, the bias in band location on 9 January can be explained by a premature (i.e., earlier than observed) northward migration of the band at this time (not shown). The observed band was mostly stationary at this time and did not begin to move northward until $\sim 1500$ UTC.

Radiosonde data were obtained from various locations around the lake (see Fig. 1b). Strong (15-25 $\mathrm{m} \mathrm{s}^{-1}$ ) westsouthwesterly winds aligned with the long axis of the lake and low near-surface temperatures resulted in a $\sim 3-\mathrm{km}$-deep convectively mixed BL within the band near the downwind shore at Henderson Harbor during IOP7 (Fig. 5a). During
IOP9, the BL within the band at Oswego was shallower $(\sim 1.5 \mathrm{~km})$, warmer (mean virtual potential temperature $\theta_{v}$ of about $266 \mathrm{~K}, \sim 6 \mathrm{~K}$ warmer than in IOP7), and much less windy $\left(<10 \mathrm{~m} \mathrm{~s}^{-1}\right)$ (Fig. $\left.5 \mathrm{~b}\right)$. Model output indicates that surface fluxes over the lake were about 4 times higher during IOP7 (Table 1), resulting in more vigorous convection as is evident in the visible satellite imagery (cf. Figs. 4a,c).

The model soundings exhibit a slight warm bias in the BL of about $1-2 \mathrm{~K}$, but they otherwise appear to correspond quite well with the observations in terms of the temperature and wind profiles (Fig. 5). The model produces a shallow layer of cold southwesterly flow at the surface in three of the four soundings (Figs. 5b-d), a feature also seen in two of the observed soundings taken south of the band. At North Redfield, New York, in IOP7 (Fig. 5c), this shallow layer is $0.4-0.5 \mathrm{~km}$ deep and

TABLE 1. General comparison of environmental conditions and band characteristics during IOP7 and IOP9. The mean and maximum reflectivity at points $\sim 25 \mathrm{~km}$ offshore $\left(Z_{\text {off }}\right)$ and $\sim 25 \mathrm{~km}$ onshore $\left(Z_{\text {on }}\right)$ were obtained using KTYX and DOW measurements at 1430 UTC 7 and 9 Jan. Maximum reflectivity is shown in parentheses. Also shown is the maximum observed 6-h precipitation (liquid equivalent) from ASOS stations at Watertown (0000-0600 UTC 7 Jan) and Fulton (0600-1200 UTC 9 Jan). WCR-based variables (described in section 4$)$ include the maximum combined mean horizontal vorticity $\overline{\omega_{h}}$ within the secondary circulation, ETH (km AGL), and maximum vertical velocity $w$ observed during the UWKA flights. WRF Model variables include mean surface wind speed $U_{\text {sfc }}$, mean 850 -hPa temperature $T_{850}$, mean surface sensible heat flux $Q_{H}$, and maximum PW over Lake Ontario at 1430 UTC 7 and 9 Jan.

\begin{tabular}{|c|c|c|c|c|c|c|c|c|c|c|}
\hline \multirow[b]{2}{*}{ IOP } & \multicolumn{3}{|c|}{$\begin{array}{c}\text { Obs: KTYX and DOW radars; ASOS } \\
\text { gauges }\end{array}$} & \multicolumn{3}{|c|}{ Obs: WCR (max values) } & \multicolumn{4}{|c|}{ WRF Model (over Lake Ontario) } \\
\hline & $Z_{\text {off }}(\mathrm{dB} Z)$ & $Z_{\text {on }}(\mathrm{dB} Z)$ & 6-h Precip (mm) & $\left(10^{-3} \mathrm{~s}^{-1}\right)$ & $\begin{array}{l}\text { ETH } \\
(\mathrm{km})\end{array}$ & $w\left(\mathrm{~m} \mathrm{~s}^{-1}\right)$ & $U_{\mathrm{sfc}}\left(\mathrm{m} \mathrm{s}^{-1}\right)$ & $T_{850}\left({ }^{\circ} \mathrm{C}\right)$ & $Q_{H}\left(\mathrm{~W} \mathrm{~m}^{-2}\right)$ & $\mathrm{PW}(\mathrm{mm})$ \\
\hline 7 & $16.7(25.5)$ & $18.6(30.0)$ & 14.5 & 5.0 & 2.9 & 10.0 & 19.5 & -24.6 & 670.0 & 2.8 \\
\hline 9 & $7.0(20.6)$ & $9.1(18.0)$ & 0.5 & 9.7 & 1.7 & 5.8 & 7.1 & -12.9 & 162.4 & 4.5 \\
\hline
\end{tabular}



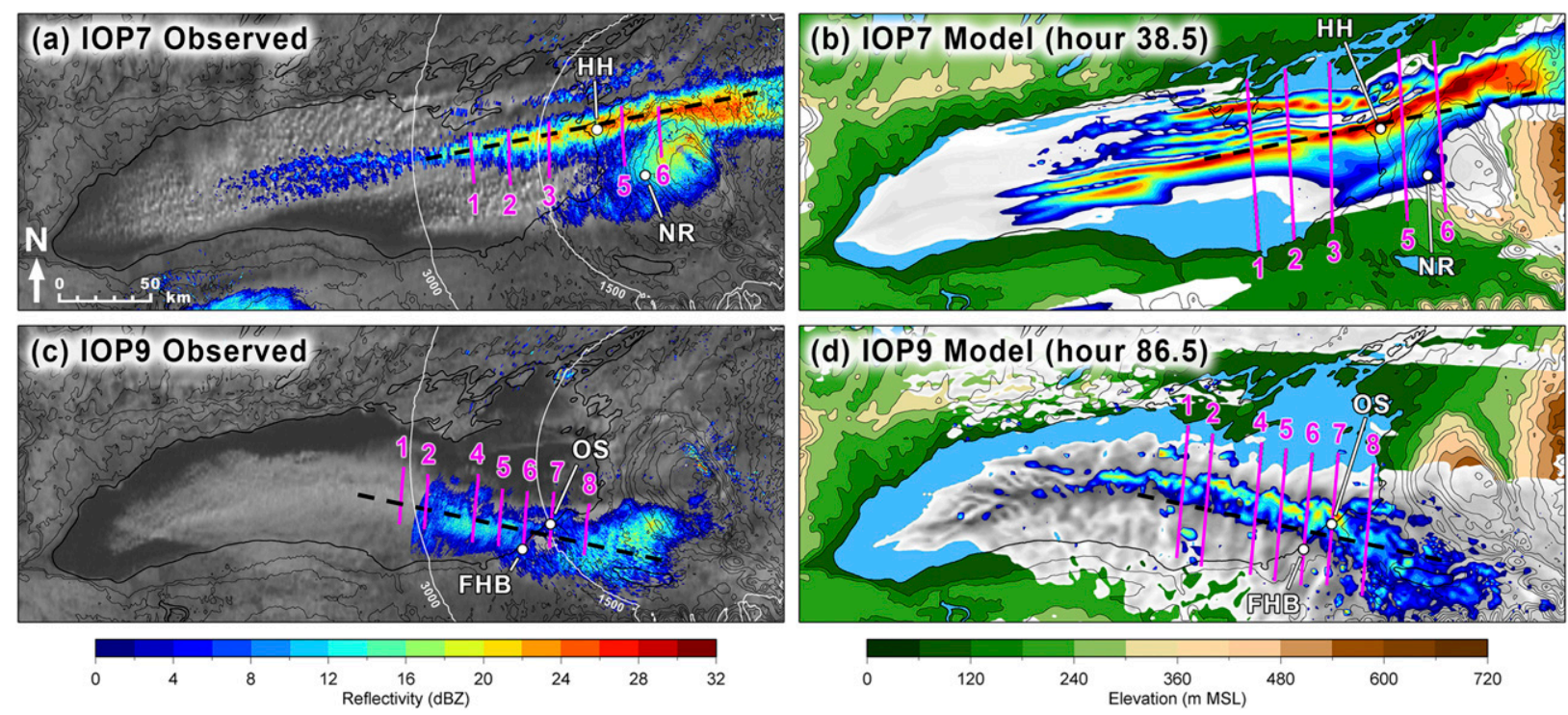

FIG. 4. KTYX and KBUF $0.5^{\circ}$ base reflectivity and GOES-13 visible satellite imagery for (a) IOP7 at 1430 UTC 7 Jan and (c) IOP9 at 1430 UTC 9 Jan and including $0.9^{\circ}$ reflectivity over the lake from DOW7 at Fair Haven Beach (FHB). Also shown is the 1.33-km-domain WRF Model reflectivity from the 14th half- $\eta$ level ( $\sim 1000 \mathrm{~m}$ AGL over the lake) and total condensed water (liquid + ice) mixing ratio (grayscale; every $0.025 \mathrm{~g} \mathrm{~kg}^{-1}$ ) for (b) IOP7 at 1430 UTC 7 Jan (forecast hour 38.5) and (d) IOP9 at 1430 UTC 9 Jan (forecast hour 86.5). UWKA flight legs (solid magenta lines), KTYX beam heights (white contours; m AGL), and mean band orientation (dashed black lines) are shown in (a) and (c). Model transects (solid magenta lines) are shown in (b) and (d). Locations of soundings from Henderson Harbor (HH), North Redfield (NR), Oswego (OS), and FHB are also plotted.

about $4-6 \mathrm{~K}$ colder than the near-surface air within the band at Henderson Harbor, $40 \mathrm{~km}$ to the northwest (Fig. 5a). The cold layer is even shallower at Fair Haven Beach in IOP9 (Fig. 5d), about $0.1-0.3 \mathrm{~km}$ deep in both the model and the observations. In short, the model captures the mesoscale precipitation structure as well as the thermodynamic and wind profiles of the observed LLAP band reasonably well throughout the event. Therefore, model output can be used to gain insight into the dynamic and kinematic environment during this event.

\section{c. IOP7 analysis}

\section{1) WCR OBSERVATIONS}

Vertical profiles of WCR reflectivity, $w$, and $u_{\text {normal }}$ from three flight legs $(1,3$, and 5) in IOP7 are presented in the top three panels of Figs. 6-8. Along leg 1, flown farthest west over the lake, the WCR observations show a well-organized LLAP band just over $2.0 \mathrm{~km}$ in depth (Fig. 6a). The band was accompanied by a relatively deep $\sim 5 \mathrm{~m} \mathrm{~s}^{-1}$ main updraft. Numerous convective updrafts and downdrafts of shallower depth were also present within the band (Fig. 6b). Some of these updrafts were collocated with areas of locally weaker reflectivity due to the lofting of hydrometeors (Houze 2014; Jensen et al. 2020). A cross-band secondary circulation was present, as indicated by the shallow layer of weakly convergent inflow near the surface and divergent outflow aloft (Fig. 6c).

Farther east along leg 3, the band was deeper and more intense (Figs. 7a,b). Maximum vertical velocities within the strongest and deepest convective updrafts, including the main updraft, were as large as $8-10 \mathrm{~m} \mathrm{~s}^{-1}$ (Fig. 7b). The secondary circulation was more organized and symmetric along this leg, with the cross-band flow pattern indicating the presence of two broad, counterrotating vortices on either side of the main updraft (Fig. 7c). This flow pattern (i.e., divergence above convergence) likely explains why reflectivity within the band tilted inward at low levels and outward aloft (Fig. 7a).

Just inland along leg 5, reflectivity was slightly higher and the band slightly deeper (Fig. 8a). WCR reflectivity reached $\sim 16 \mathrm{dBZ}$, near the maximum for a $\mathrm{W}$-band radar. Thus, the inland intensification of the LLAP band evident on the KTYX (S band) reflectivity map (Fig. 4a; Table 1) is not as pronounced in the WCR reflectivity transects. Although the main updraft within the band was weaker along this leg (Fig. 8b), a coherent secondary circulation was still present (Fig. 8c). The separate region of enhanced precipitation over Tug Hill seen in Fig. 4a can also be seen near the southern end of the leg in Fig. 8a. This is not simply orographic enhancement; it was associated with a shallow layer of locally stronger southerly flow and a rather broad $\sim 5 \mathrm{~m} \mathrm{~s}^{-1}$ updraft above the leading edge of this layer (Figs. 8b,c). In section 5a, it is shown that this leading edge was likely an LBF.

To assess the strength of the secondary circulation, mean horizontal vorticity $\omega_{h}$ values were calculated along each leg, with $\omega_{h}$ defined as

$$
\omega_{h}=\frac{\partial w}{\partial x}-\frac{\partial u_{\text {normal }}}{\partial z}
$$

where $x$ is positive to the north and $z$ is positive upward. The measurements were taken from within two adjacent 
IOP7
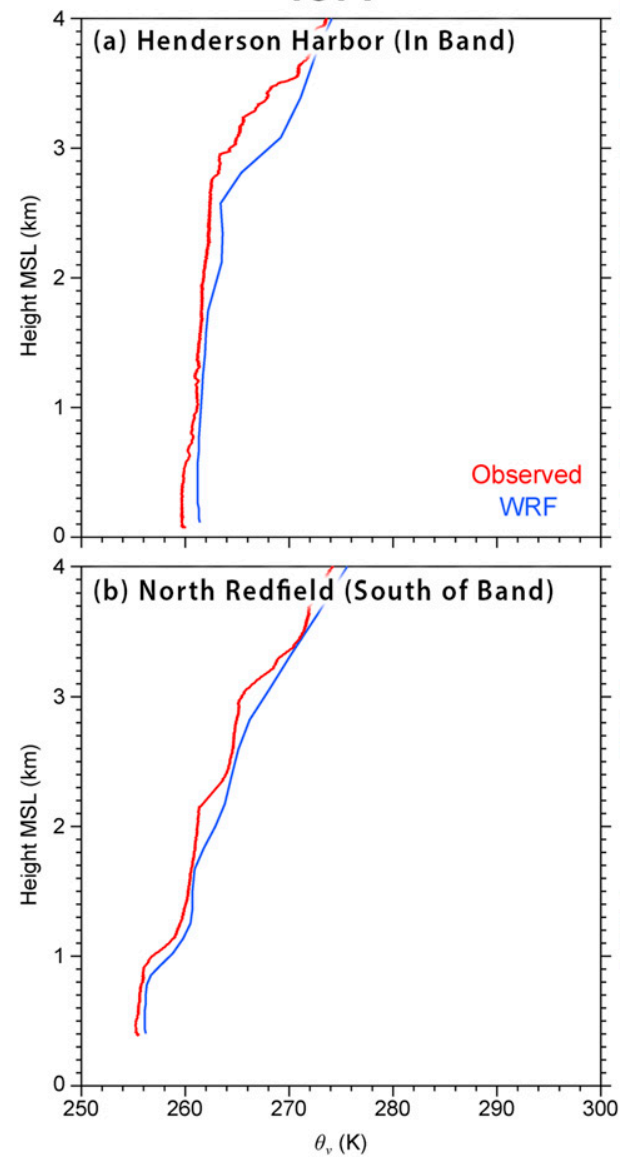

IOP9
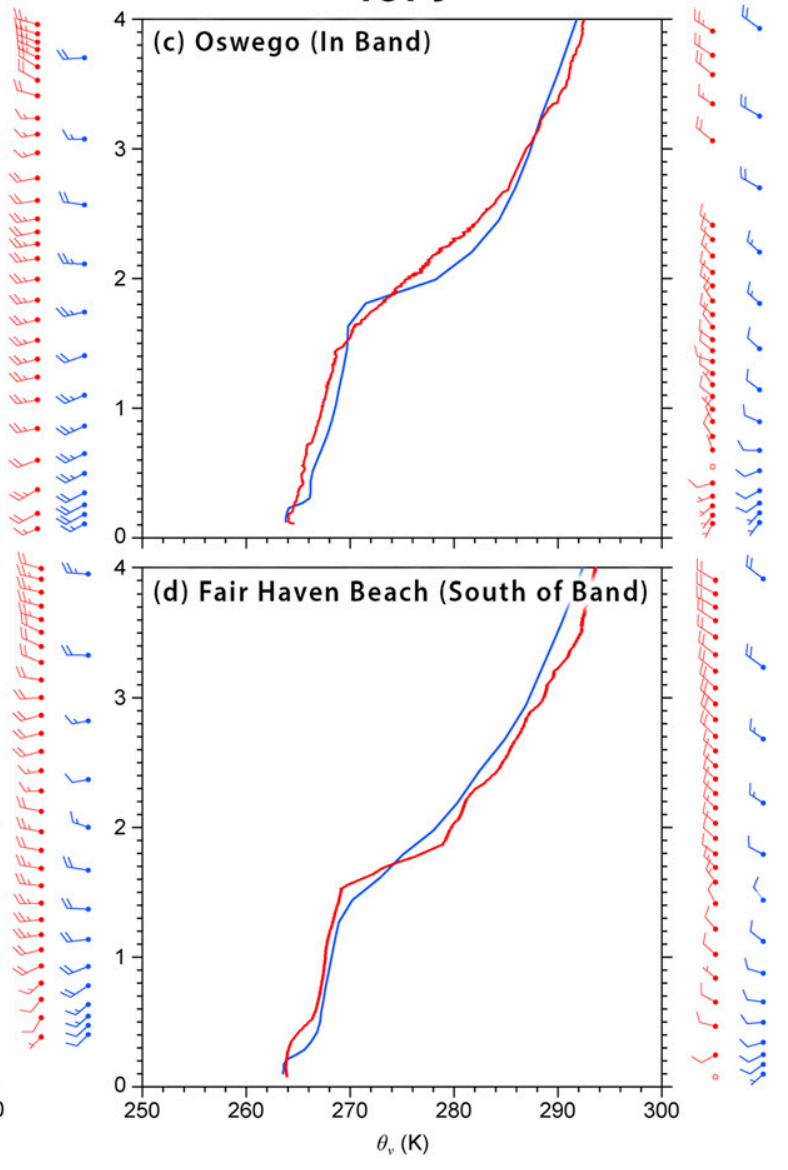

FIG. 5. Observed (red) and WRF Model (blue; 1.33-km domain) sounding comparison for IOP7 at 1415 UTC 7 Jan and IOP9 at 1415 UTC 9 Jan (see Fig. 4 for locations). Shown are virtual potential temperature and the horizontal wind barbs. One full barb is $10 \mathrm{~m} \mathrm{~s}^{-1}$.

rectangular boxes on either side of the primary updraft (see magenta boxes in Figs. 6c, 7c, and 8c). Each box is $10 \mathrm{~km}$ wide (if flight leg length allows) and extends vertically from 0.1 to $2.3 \mathrm{~km}$ MSL. The $\omega_{h}$ value averaged within the area of each box represents the circulation strength within that box (divided by its area). The $\omega_{h}$ values generally ranged from about $3 \times 10^{-3}$ to $6 \times 10^{-3} \mathrm{~s}^{-1}$ and tended to be slightly larger within the southern box (i.e., the southern branch of the circulation), especially over the water (Fig. 9a). Moreover, the combined mean $\omega_{h}$ increased between legs 1 and 3 and were lower along legs 5 and 6 , indicating that the entire circulation strengthened from west to east over the water and weakened as the band moved inland.

\section{2) MOdEL CROSS SECTIONS}

The WCR profiles are compared with cross sections of corresponding model output. The model $u_{\text {normal }}$ wind lies along the same axis as the DD $u_{\text {normal }}$ component (section $2 \mathrm{a}$ ), so the two can be directly compared. The comparison of WCR and model reflectivity is more qualitative since the two variables are not the same. The reflectivity derived from the model hydrometeor size distribution following the P3 scheme (Morrison and Milbrandt 2015) assumes Rayleigh scattering, where reflectivity is dominated by the largest particles. However, for $\mathrm{W}$-band radars like the WCR, Rayleigh scattering is valid only for particles less than $\sim 0.5 \mathrm{~mm}$ in diameter (Matrosov 2007; Chu et al. 2017), whereas larger particles are Mie scatterers. Thus, different ranges of reflectivity are plotted in the corresponding WCR and model panels in Figs. 6-8 since maximum reflectivity from the WCR tends to saturate around $15 \mathrm{dBZ}$, lower than the model reflectivity.

The IOP7 cross sections, shown by the magenta lines in Fig. 4b, are oriented along the UWKA flight legs but are longer ( $\sim 90 \mathrm{~km}$ in length). Examination of cross sections 1 , 3 , and 5 [panels (d)-(f) in Figs. 6-8] shows that the model produces a dominant LLAP band that strengthens from west to east and is accompanied by both a deep main updraft and an organized secondary circulation. Given that the model horizontal resolution is more than two orders of magnitude coarser than that of the WCR, the model is unable to capture the fine details and broad distribution of the 


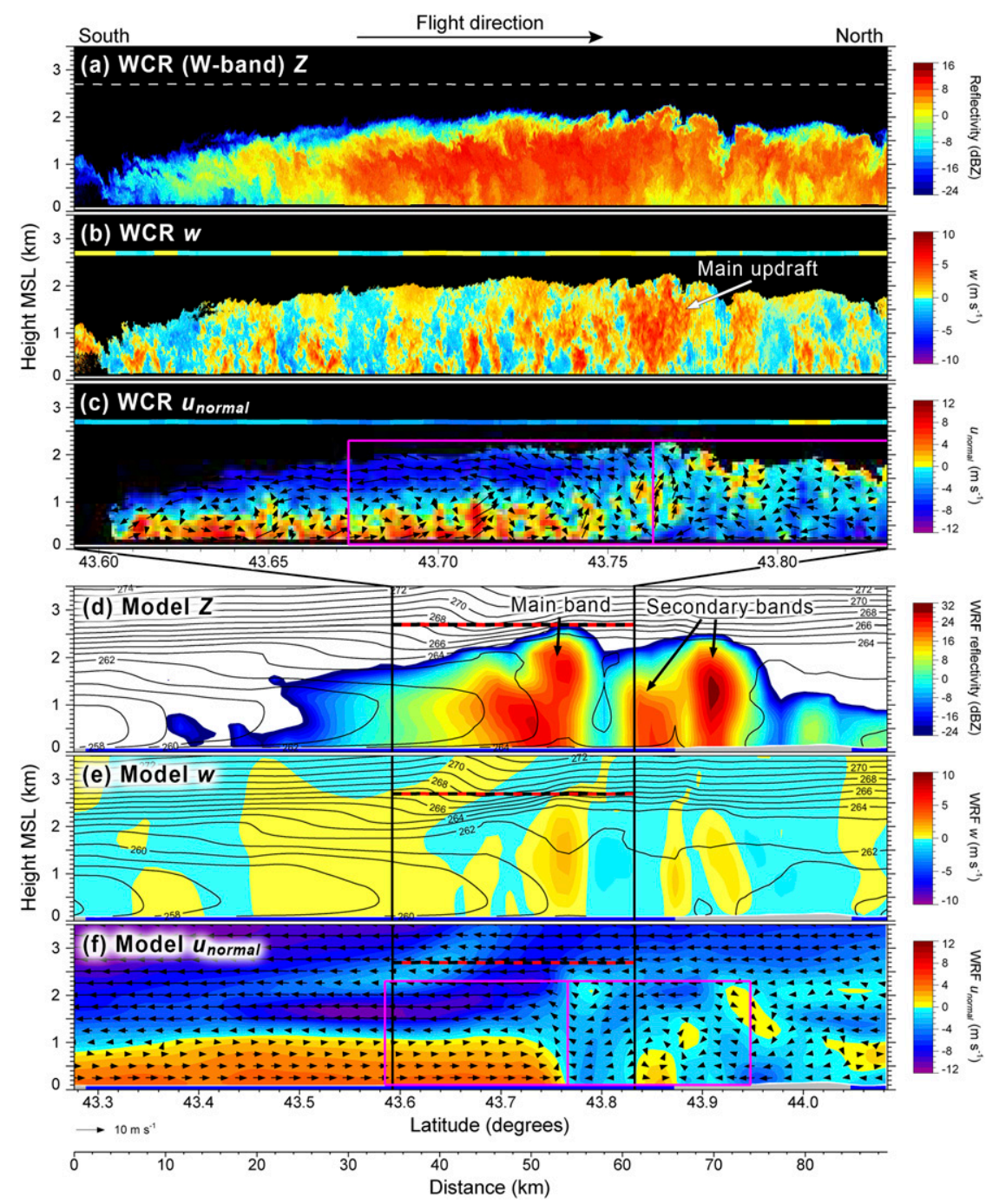

FIG. 6. Comparison of IOP7 WCR observations along leg 1 (1338-1343:15 UTC; see Fig. 4a for location) and WRF Model output from the $1.33-\mathrm{km}$ domain along cross section 1 (1340 UTC; see Fig. 4b for location) on 7 Jan. Shown from the WCR are (a) reflectivity $Z$, (b) air vertical velocity $w$, and (c) $u_{\text {normal }}$ and $2 \mathrm{D}$ flow vectors $\left(u_{\text {normal }}, w\right)$. Shown from the model are (d) $Z$ (shaded) and $\theta_{e}$ (contours every $1 \mathrm{~K}$ ), (e) $w$ (shaded) and $\theta_{v}$ (contours every $1 \mathrm{~K}$ ), and (f) $u_{\text {normal }}$ and wind vectors. UWKA flight level is shown by the white dashed line in (a) and by the black and red dashed lines in (d)-(f). Corresponding UWKA in situ measurements of $w$ and $u_{\text {normal }}$ are color shaded at flight level in (b) and (c), respectively. The ground or lake is shown as a white line in (a)-(c). The ground is shaded in gray and the lake is shaded in blue in (d)-(f). Mean horizontal vorticity is calculated from within the magenta boxes positioned south and north of the main updraft in (c) and (f).

convective vertical motions (Figs. 6e, 7e, and 8e) (Jensen et al. 2020). The position of the model band agrees quite well with the observed band over the lake (Figs. 6d and 7d), but the model positions the LLAP band too far north over land (Fig. 8d; cf. Figs. 4a,b).

Within cross sections 1 and 3 , the main band is situated along and somewhat tilted over the northern edge of a layer of slightly cooler air to the south (Figs. 6d,e and 7d,e). The secondary circulation is more organized to the south of the main updraft within this cooler air, where the inflow and outflow layers are stronger (Figs. 6f and 7f). The flow to the north of the main updraft along both cross sections lacks well-organized outflow aloft, perhaps due in part to the presence of the secondary band(s) (Fig. 4b). This rather asymmetric band structure was alluded to in the WCR data along leg 1 (Fig. 6a) but was not as apparent along leg 3 (Fig. 7a), where the main band and its secondary circulation were more symmetric. 

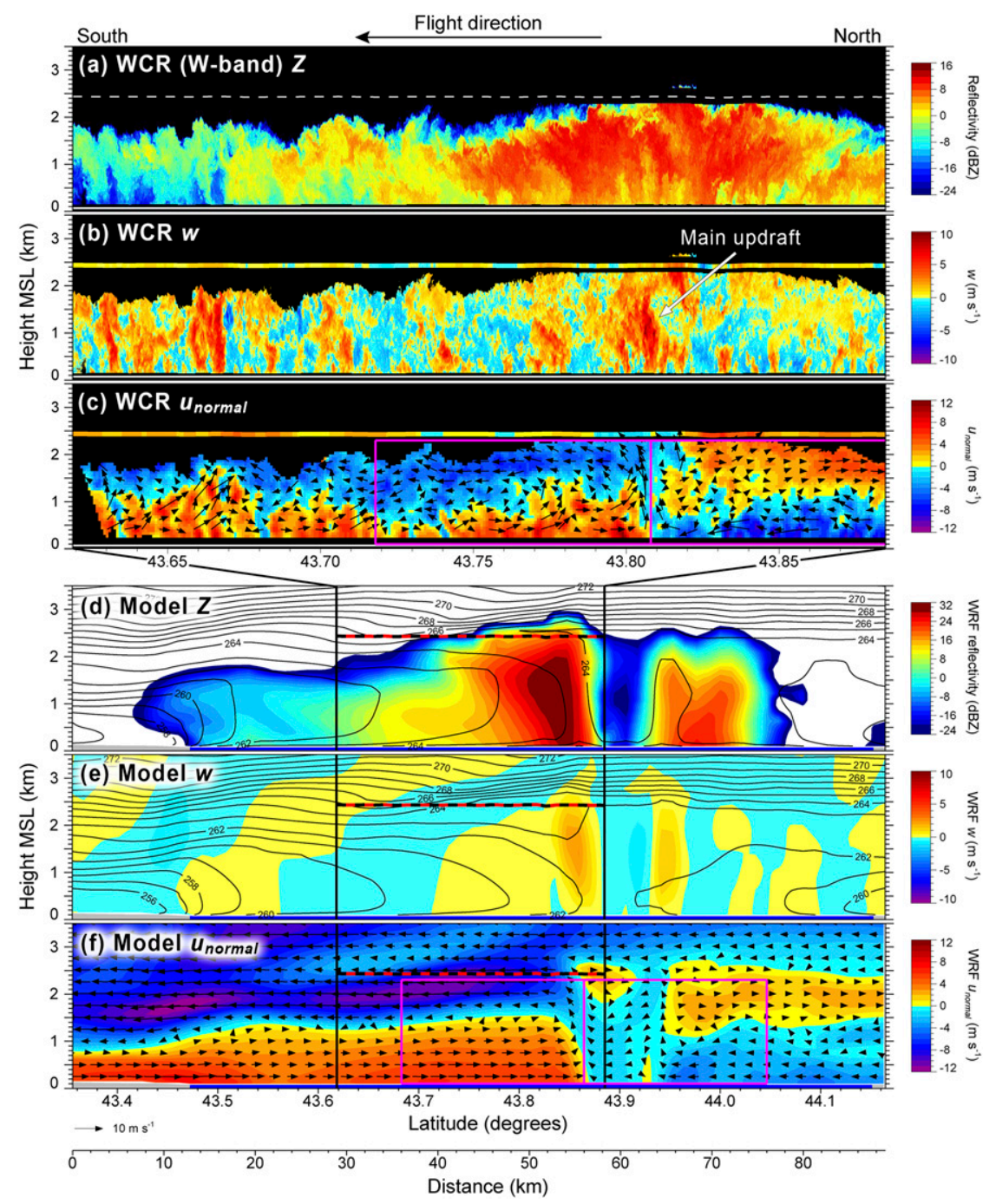

FIG. 7. As in Fig. 6, but for leg 3 (1358-1403:30 UTC) and model cross section 3 (1400 UTC).

The main updraft within the band is at its strongest over land along cross section 5 and extends as high as $3 \mathrm{~km}$ MSL (Figs. 8d,e). Notably, the inflow and outflow layers within the northern branch of the circulation are stronger and more organized here, resulting in a more symmetric secondary circulation (Fig. 8f). The southerly inflow is composed of two distinct layers: a deep layer of warmer lake-modified air immediately south of the band and a shallow layer of cooler, stronger inflow farther south. The latter is associated with an area of enhanced reflectivity and a $\sim 2 \mathrm{~m} \mathrm{~s}^{-1}$ updraft situated above its leading edge (Figs. 8d,e). The WCR reveals similar flow features along the southern end of leg 5 (see Figs. 8a-c), suggesting that a shallow layer of cooler air was present east of the lake at this time. The 1414 UTC radiosonde data from North Redfield (located near the south end of leg 5) confirm the presence of such a layer, about $0.4-0.5 \mathrm{~km}$ in depth (Fig. $5 \mathrm{c}$ ).

The simulated mean $\omega_{h}$ is calculated within identically sized rectangular boxes for cross sections 1, 3, and 5 (see
Figs. 6f, 7f, and 8f). These boxes are $20 \mathrm{~km}$ wide (twice as wide as for the WCR), $2.2 \mathrm{~km}$ deep (same as WCR), and are again situated on either side of the main LLAP band updraft. Because there are no other significant circulations within $20 \mathrm{~km}$ of the LLAP band, the model and WCR mean $\omega_{h}$ values can be compared directly, and they compare well in magnitude (Figs. 9a,c). As observed, the southern branch of the circulation is consistently stronger than the northern branch, especially over the lake along cross sections 1-3 (also see Figs. 6f and 7f). In disagreement with WCR observations, the combined mean $\omega_{h}$ of the model secondary circulation continuous to increase inland, at least up to cross section 6 (Fig. 9c).

The maximum cloud depth [using $-10 \mathrm{dBZ}$ as the echo-top height $(\mathrm{ETH})]$ within the simulated band increases by $\sim 0.6 \mathrm{~km}$ from west to east (Fig. 10a), consistent with another modeling study of this LLAP band (Eipper 2017, chapter 3). WCR observations indicate a slightly shallower band, but a similar 

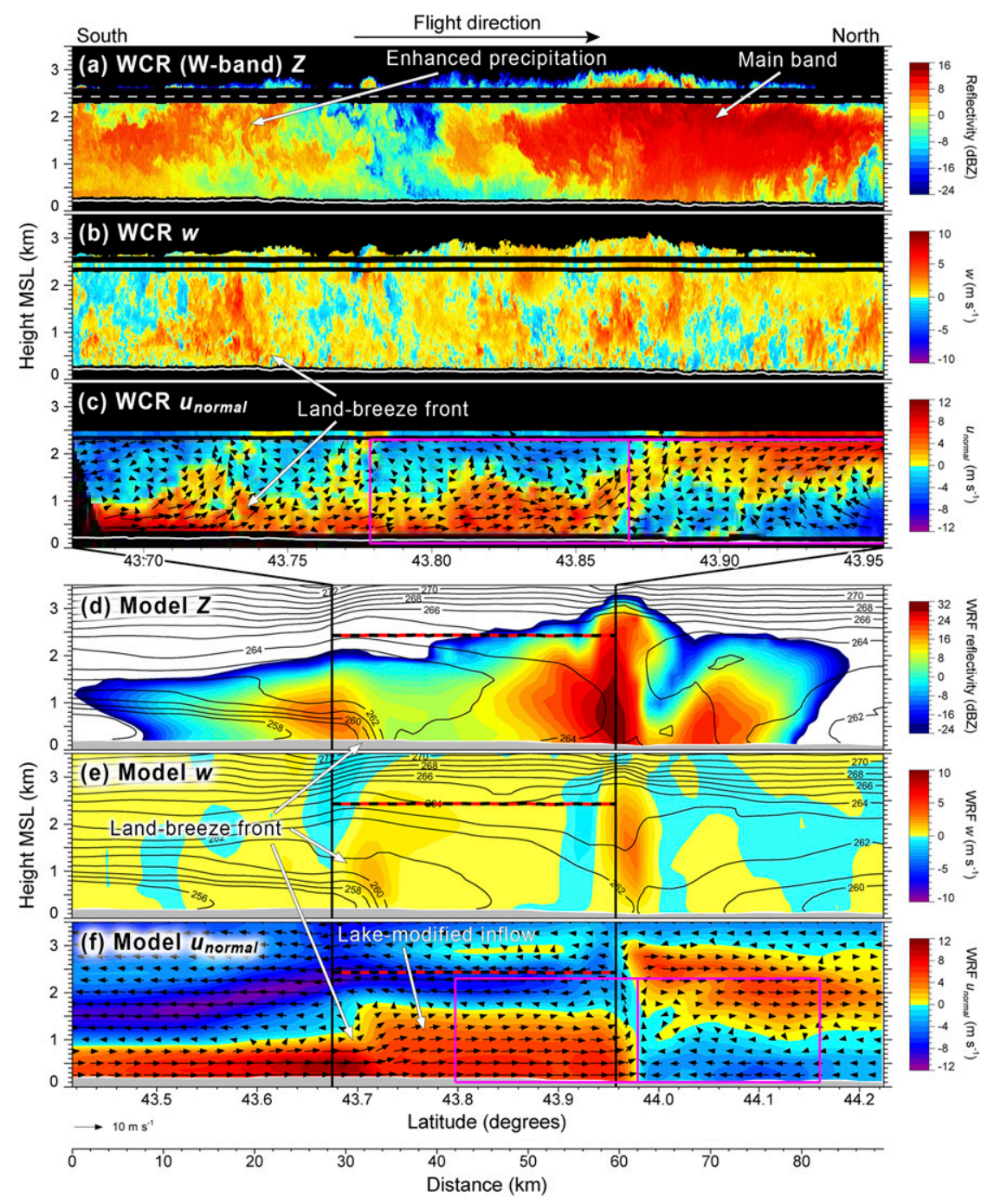

FIG. 8. As in Fig. 6, but for leg 5 (1418-1424 UTC) and model cross section 5 (1420 UTC).

west-to-east increase in depth (Fig. 10a). Maximum updrafts in the model are about $1-2 \mathrm{~m} \mathrm{~s}^{-1}$ (i.e., about $25 \%-50 \%$ ) weaker over the lake than those in the WCR vertical velocity field, the latter of which was low-pass filtered to match the model resolution (Fig. 10c). However, they show much better agreement, within about $0.5 \mathrm{~m} \mathrm{~s}^{-1}$, inland along legs 5 and 6 where updraft maxima weakened.

\section{d. IOP9 analysis}

\section{1) WCR OBSERVATIONS}

WCR observations show a much shallower, less organized band of precipitation over the lake in IOP9, relative to IOP7. Three geographically corresponding legs $(2,5$, and 8) were examined for IOP9 (Figs. 11-13, respectively). To the north along each leg, reflectivity was highest near flight level and gradually weakened closer to the surface (Figs. 11a, 12a, and 13a), implying that snow may have sublimated toward the surface within drier air advected from the north. Along leg 2, the band-normal winds were primarily out of the north (Fig. 11c), except for a shallow layer of strong southerly inflow feeding into the main updraft. Interestingly, the weaker inflow from the north ascended over this shallow layer within the updraft, producing a well-defined, but rather asymmetric, secondary circulation on the southern side of the updraft. This asymmetry is consistent with a baroclinic environment, in which the updraft and precipitation are tilted over cooler air south of the band (e.g., Figs. 12a,b). A rotorlike feature was also present at the leading edge of the southerly inflow layer, revealed by both a vertical velocity couplet (Fig. 11b) and the 2D flow vectors (Fig. 11c). A similar feature was also observed along leg 5 (Figs. 12b,c). It is worth pointing out that shear-generated horizontal vortices are sometimes observed above or within the head of density currents (Markowski and Richardson 2010, chapter 5.3). These characteristics support the argument that the air 

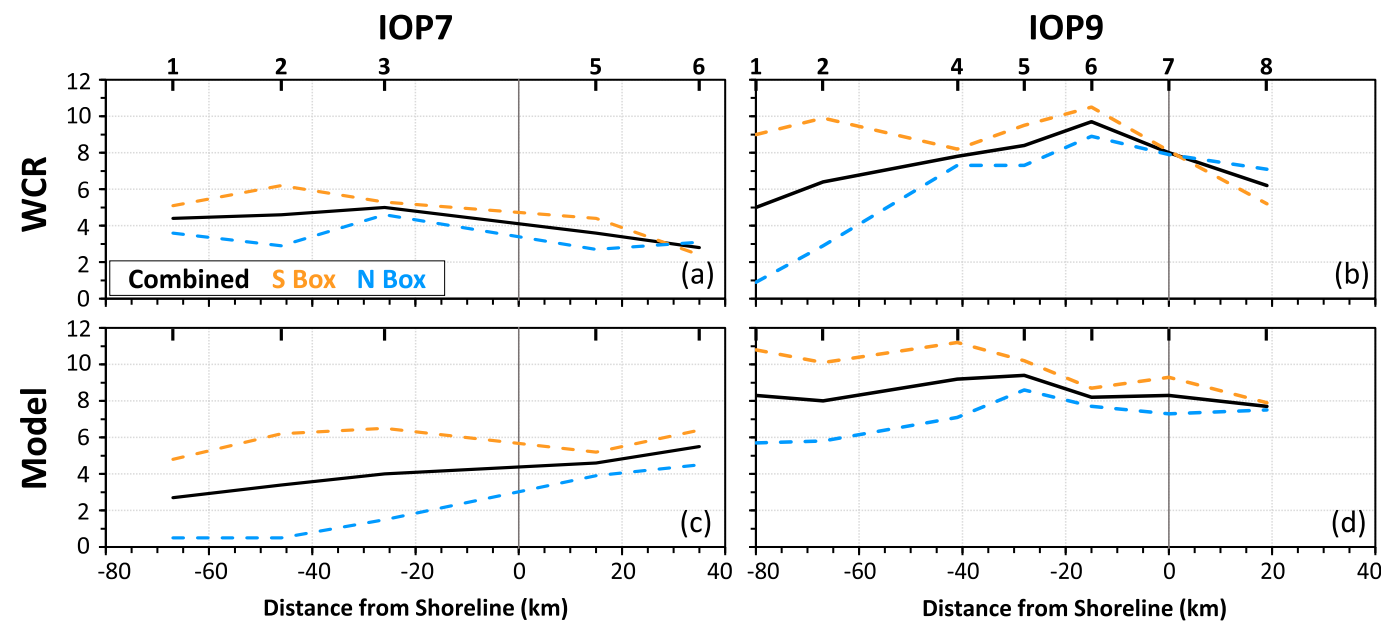

FIG. 9. Absolute mean horizontal vorticity $\omega_{h}\left(10^{-3} \mathrm{~s}^{-1}\right)$ for (left) IOP7 and (right) IOP9 from the (a),(b) WCR vertical profiles along each leg and (c),(d) WRF Model (1.33-km domain) cross sections. Leg and cross-sectional numbers are labeled above (a) and (b). Along each, mean $\omega_{h}$ values were calculated from within two adjacent, identically sized rectangular boxes situated immediately to the south ( $\mathrm{S}$ box; yellow dashed line) and north ( $\mathrm{N}$ box; blue dashed line) of the primary updraft. The combined mean $\omega_{h}$ (black solid line) is the average of the two. The magenta boxes in (c) and (f) of Figs. 6-8 and 11-13 show the locations of these areas for the corresponding legs and cross sections, respectively.

within the southerly inflow layer was cooler than the lowlevel inflow from the north.

Again moving from west to east, the band's reflectivity was highest near the shoreline along leg 5 (Fig. 12a) and weaker inland along leg 8 (Fig. 13a). Overall, the secondary circulation was more developed along leg 5, with welldefined layers of convergence and divergence (Fig. 12c). Leg 8 was flown mostly over land but did pass over the lake at its northern end (see Fig. 4c). The band exhibited signs of disorganization and weakening along this leg. The main updraft, surface convergence, and secondary circulation remained situated along the shoreline to the north and were almost completely displaced from the primary area of LE precipitation over land to the south (Figs. 13a-c). There were well-defined main updrafts along the offshore legs (Figs. 11b and 12b), although they were generally weaker than in IOP7. However, the updrafts along leg 8 were very weak and uniform $\left(<2 \mathrm{~m} \mathrm{~s}^{-1}\right.$; Fig. $\left.13 \mathrm{~b}\right)$, implying

\section{OP7}
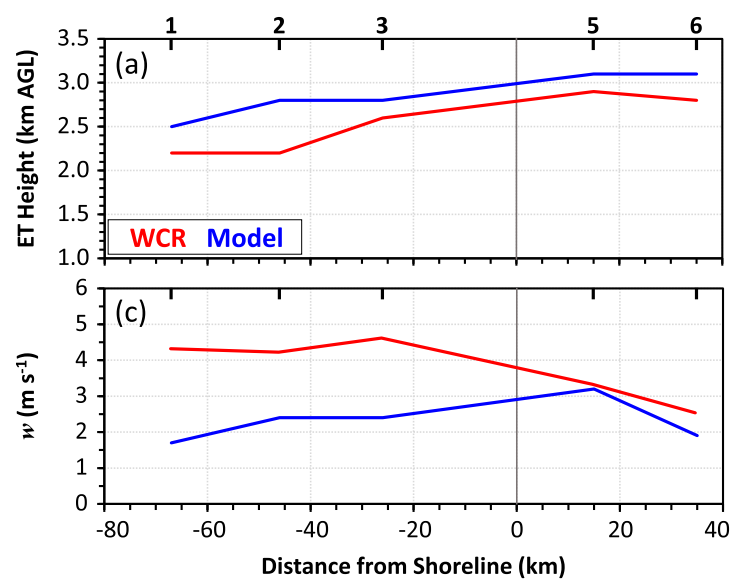
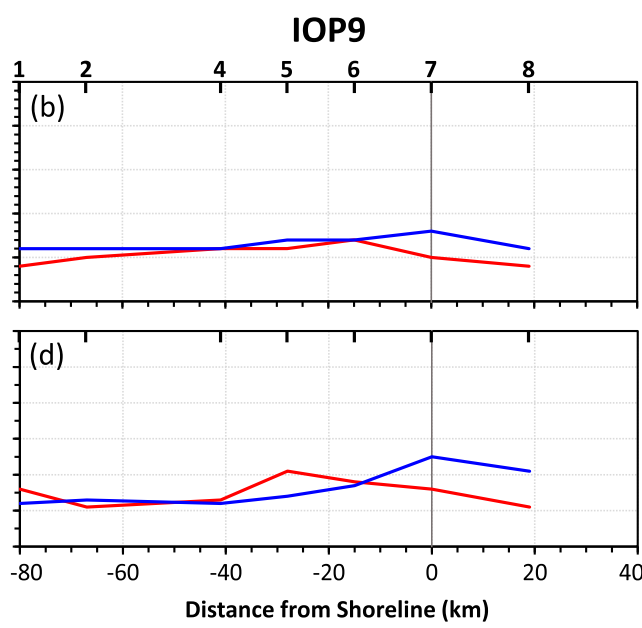

FIG. 10. WCR (red) and WRF Model (blue; 1.33-km domain) comparison of (a),(b) maximum echo-top heights and (c),(d) maximum air vertical velocity $w$ along each leg or cross section on (left) IOP7 and (right) IOP9. Echo-top heights are based on the maximum height of the $-10-\mathrm{dB} Z$ contour. The WCR velocities have been low-pass filtered to match the horizontal resolution of the model. Leg and cross-sectional numbers are labeled above (a) and (b). 

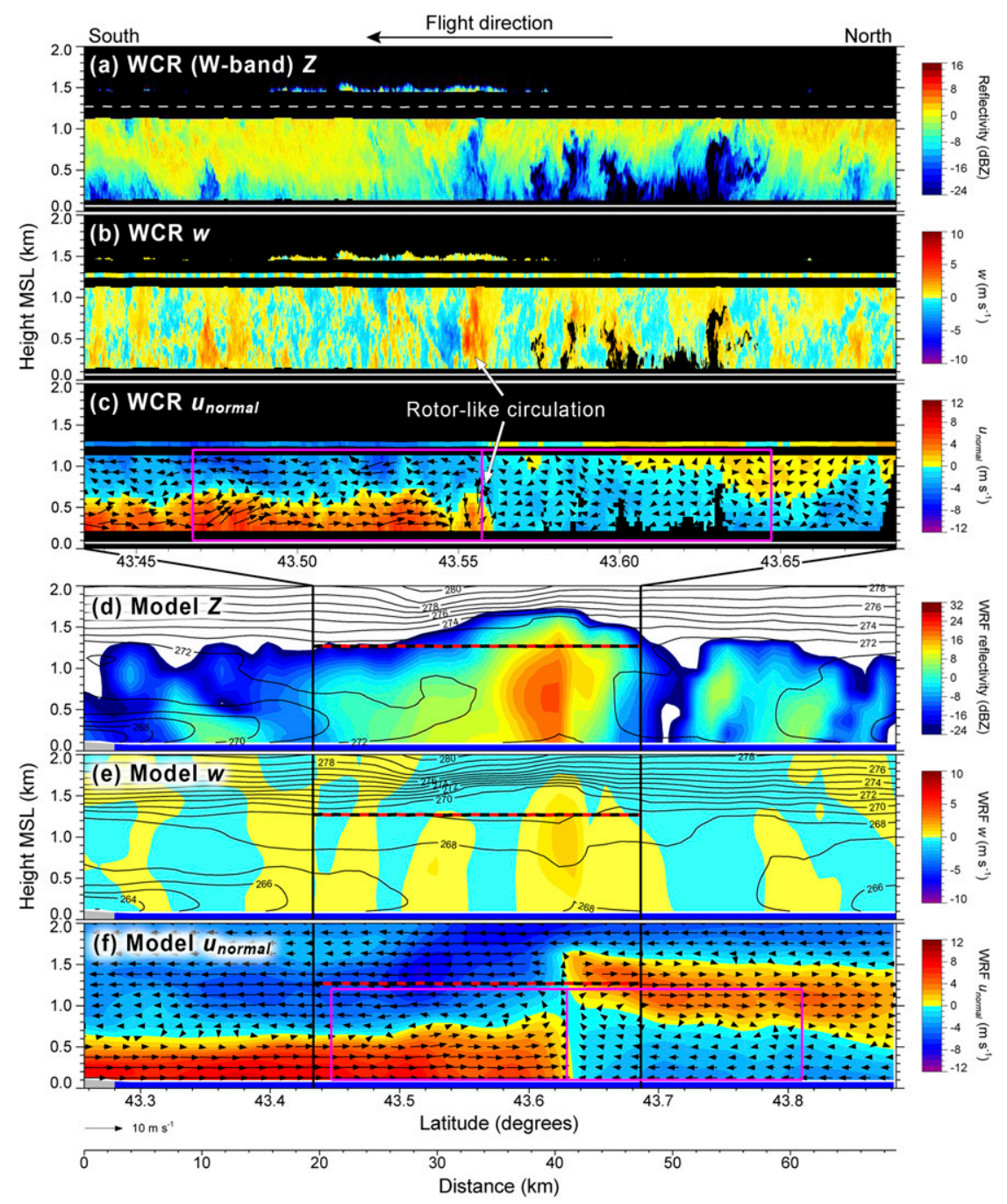

FIG. 11. As in Fig. 6, but for IOP9 along leg 2 (1334:20-1340 UTC) and model cross section 2 (1340 UTC) on 9 Jan.

an inland transition to stratiform precipitation. This inland weakening departs significantly from what was observed in IOP7, when the band remained organized as it moved inland.

The secondary circulation was shallower, but stronger, during this flight relative to IOP7. Combined mean $\omega_{h}$ values $^{3}$ ranged from $5.0 \mathrm{~s}^{-1}$ along leg 1 to as high as $9.7 \mathrm{~s}^{-1}$ along leg 6 (Fig. 9b). The band asymmetry seen in Figs. 11-13 is also evident here, especially along legs 1 and 2 where the southern branch of the circulation was much stronger than the northern branch. This difference in strength was much less pronounced along legs 4-8 as the northern branch of the circulation intensified.

\footnotetext{
${ }^{3}$ For IOP9, the boxes used to calculate mean $\omega_{h}$ only extended from 0.1 to $1.2 \mathrm{~km}$ MSL given the shallow depth of the band, but they were of the same length as in IOP7 $(10 \mathrm{~km})$ where WCR data were available.
}

\section{2) MODEl CROSS SECTIONS}

Simulated cross sections 2,5 , and 8 are presented in the bottom three panels of Figs. 11-13, respectively; their locations are shown in Fig. 4d. The model produces a LLAP band and secondary circulation that are similar in many ways to what was observed. For example, over the lake, the simulated band is somewhat asymmetric in its vertical structure since its main updraft tends to be positioned on the northern side of the band with most of the precipitation extending southward over the low-level inflow (Figs. 11d,e and 12d,e). Also, the main updraft exhibits a slight southward tilt with height along cross section 5, within which the northerly inflow ascends over the southerly inflow (e.g., Figs. 12e,f). In addition, the secondary circulation is typically stronger within its southern branch (cf. Figs. 9b,d) and is stronger as a whole than the IOP7 secondary circulation (cf. Figs. 9c,d), as was observed. In fact, the combined mean $\omega_{h}$ values from the IOP9 simulated secondary circulation along cross sections $4-8$ (Fig. 9d) range from 7.7 to $9.4 \mathrm{~s}^{-1}$, which 


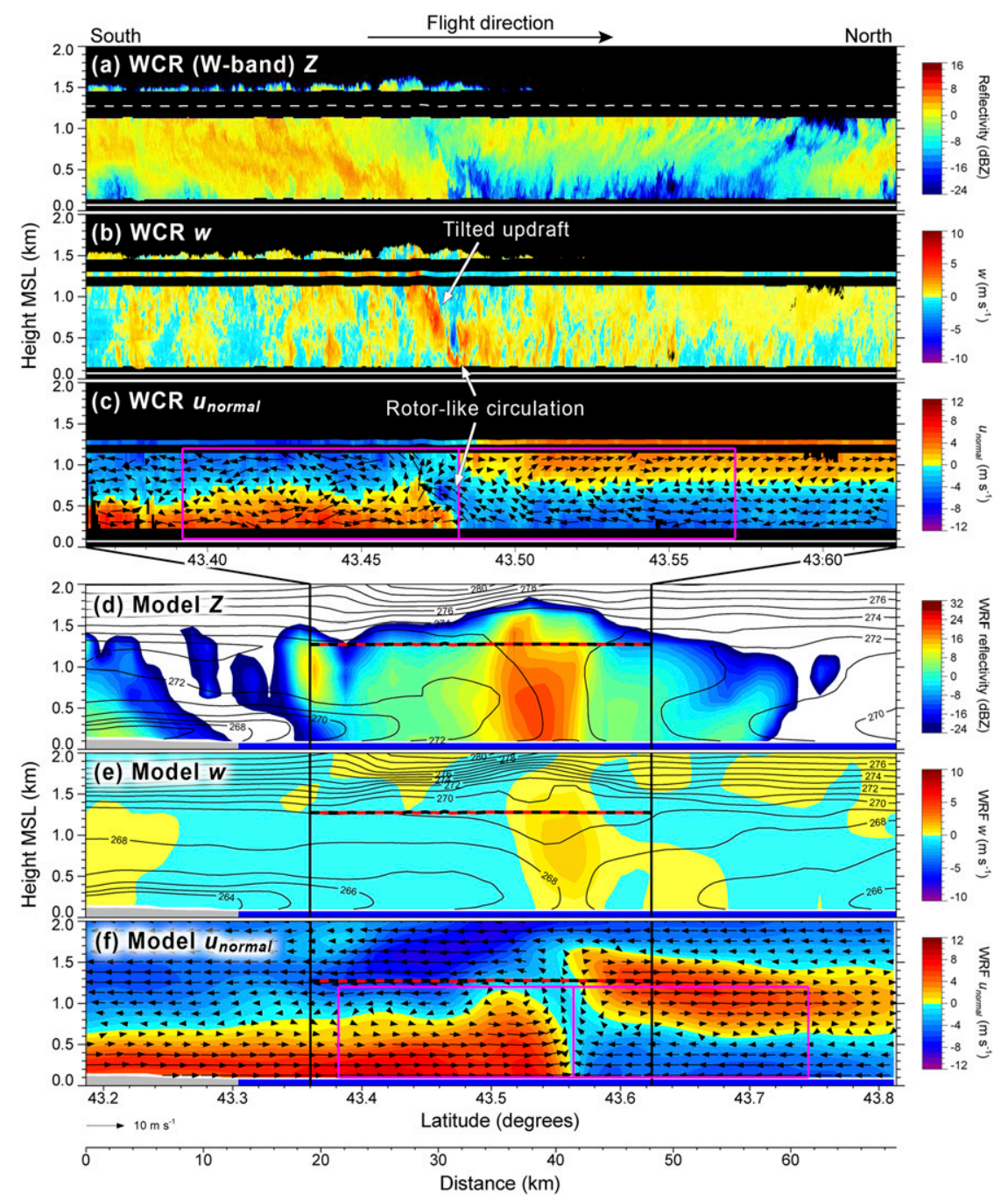

FIG. 12. As in Fig. 6, but for IOP9 along leg 5 (1402:20-1408:30 UTC) and model cross section 5 (1400 UTC) on 9 Jan.

compare reasonably well with the observations along legs 4-8 (cf. Figs. 9b,d). Furthermore, the model captures the northward displacement of the secondary circulation along the lake shoreline, and the resulting separation of this circulation from the precipitation, along cross section 8 (Figs. 13d-f). The simulated maximum echo-top heights agree well with observations, increasing only slightly from west $(\sim 1.5 \mathrm{~km} \mathrm{AGL})$ to east $(\sim 1.7 \mathrm{~km}$ AGL) over the lake and then decreasing slightly by leg 8 (Fig. 10b). The simulated maximum vertical velocities range from about 1.0 to $2.5 \mathrm{~m} \mathrm{~s}^{-1}$, reasonably close to the spatially degraded maximum WCR values for most of the cross sections (Fig. 10d). These values are about half that of IOP7 (cf. Figs. 10c,d).

The asymmetry in both the simulated and observed bands during IOP9 suggests that the environment across the band is baroclinic, with the southern low-level air mass being colder. The tightly packed, tilting $\theta_{v}$ contours terminating near the shoreline along cross section 8 (Fig. 13e) are consistent with this interpretation. However, along cross sections 2 and 5, the low-level air over the lake immediately south of the band (i.e., far from the shore) is only $\sim 1 \mathrm{~K}$ cooler than the air to the north (Figs. 11e and 12e), suggesting the presence of a different convergent boundary from the one along the shoreline in cross section 8 . The cross-band baroclinity is examined further in section 5 a.

\section{WRF examination of LLAP band structures}

Now that the WRF simulation has been shown to compare well with the observations, model output can be used to further explore the differences between the LLAP band structures during the two IOPs. The first part of this analysis delves into the band's mesoscale forcing, focusing on the role of shallow baroclinic airmass boundaries and buoyancy, whereas the second part briefly examines factors related to the difference in inland penetration of the LLAP band and its precipitation on both days. 


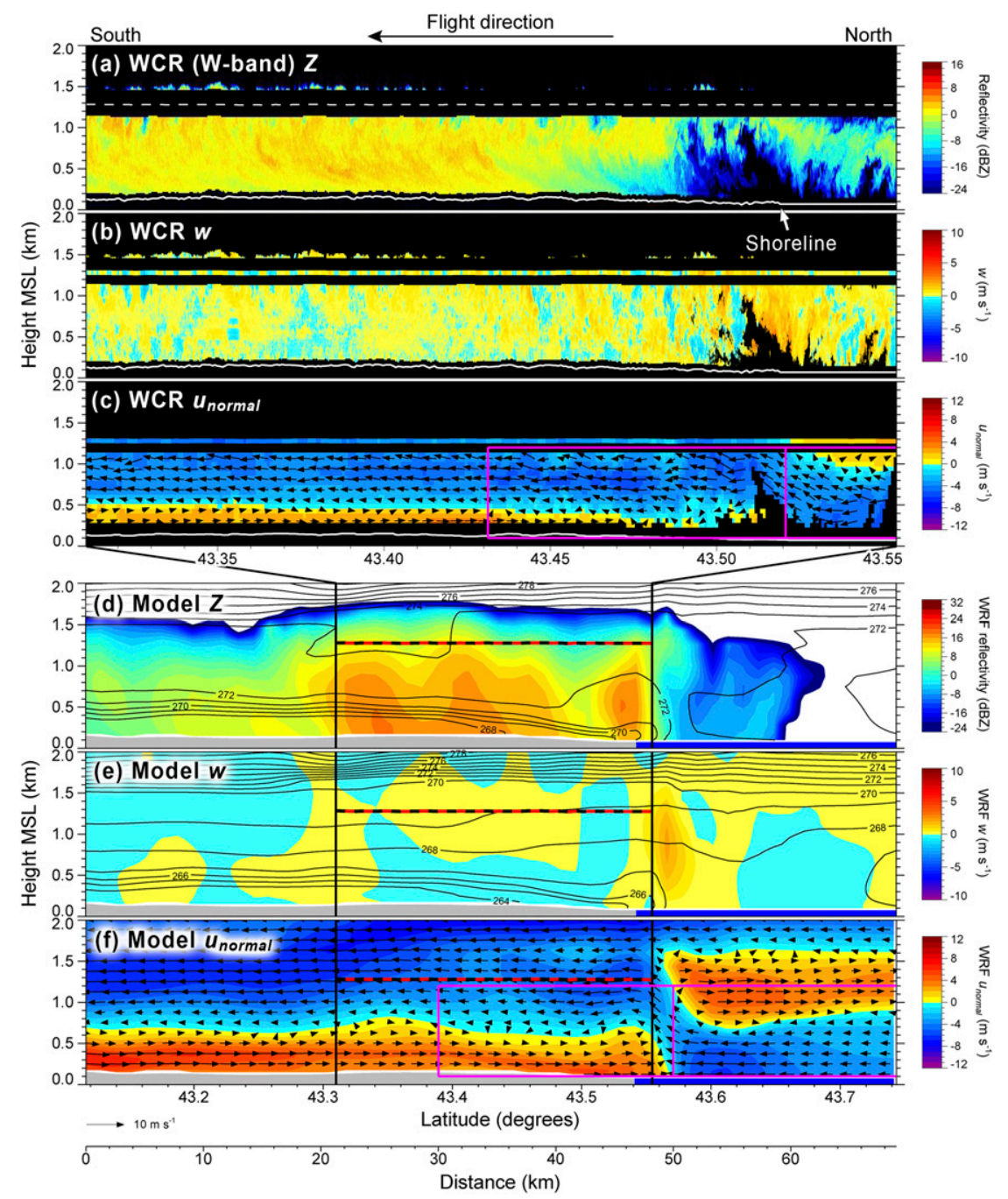

FIG. 13. As in Fig. 6, but for IOP9 along leg 8 (1430:45-1436 UTC) and model cross section 8 (1430 UTC) on 9 Jan.

\section{a. LLAP band forcing}

The simulated IOP7 LLAP band has its origins along a LBF that is defined by a surface convergence line (CL) and strong temperature gradient (Figs. 14a,c,e) situated along the western side of a bulge in the southern shoreline of the lake (hereinafter southern bulge; see Fig. 1b). During IOP7, the shoreline west of the southern bulge is parallel to the prevailing west-southwesterly surface flow and separates two distinct air masses. The IOP7 LLAP band is thus very similar to the long-lived, intense IOP2b LLAP band (Steenburgh and Campbell 2017; Bergmaier et al. 2017). The air mass to the north, having already traversed some distance across the lake, has been warmed and moistened by the warmer water below (see $\theta_{v}$ contours in Fig. 14c). The narrow strip of cooler air to the south has instead passed through the land gap between Lakes Erie and Ontario, remaining unmodified by either lake. This airmass, and the alignment of the prevailing flow with the shoreline west of the southern bulge, supports the LBF (hereinafter LBF1; Figs. 14c,e).

LBF1 separates from the curving shoreline and is advected across the lake with the prevailing flow (Figs. 14a,c). Temperature anomalies, defined as $\theta_{v}(z)-\overline{\theta_{v}}(z)$, along cross section $\mathrm{A}-\mathrm{A}^{\prime}$ indicate that the upwind environment across LBF1 is initially baroclinic, with a rather weak, shallow, thermally direct secondary circulation present on the cooler side (Fig. 15a). Further downwind over the lake (cross section B$\mathrm{B}^{\prime}$ ), gradual warming of the southern air mass — driven primarily by surface heating over Lake Ontario and perhaps enhanced by downward mixing of lake-modified air from Lake Erie-leads to weakening of the low-level baroclinic forcing across the band (Figs. 14c and 15c). Despite this, the primary CL remains strong and organized (Fig. 14c) and the band continues to deepen and intensify toward the downwind shore. The band's main updraft is likely sustained thermally and enhanced by a downstream increase in local positive buoyancy-driven in part by latent 

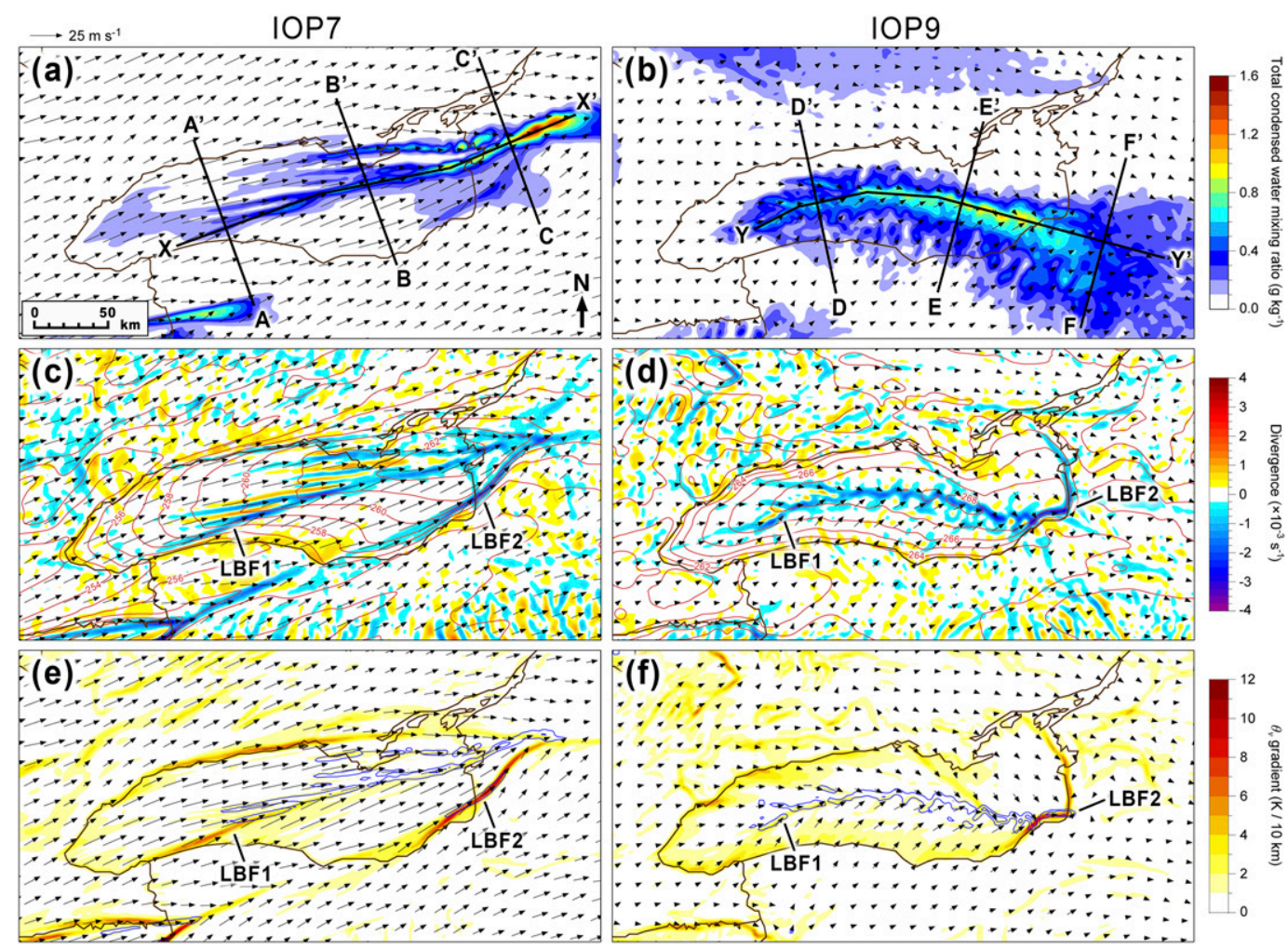

FIG. 14. WRF Model output from the 1.33-km domain showing (a),(b) column-maximum total condensed water (liquid + ice) mixing ratio, (c),(d) surface (lowest half- $\eta$ level) divergence (shaded) and $\theta_{v}$ (red contours every $1 \mathrm{~K}$ ), and (e),(f) surface $\theta_{v}$ gradient (shaded) and maximum column latent heating rate (blue contours every $5 \mathrm{~K} \mathrm{~h}^{-1}$ ) for (left) IOP7 at 1430 UTC 7 Jan and (right) IOP9 at 1430 UTC 9 Jan. Surface horizontal wind vectors are plotted in each panel, and both land-breeze fronts (LBF1 and LBF2) are labeled. Cross sections from $\mathrm{A}-\mathrm{A}^{\prime}$ through $\mathrm{F}-\mathrm{F}^{\prime}$ are shown in Fig. 15. Cross sections $\mathrm{X}-\mathrm{X}^{\prime}$ and $\mathrm{Y}-\mathrm{Y}^{\prime}$ are presented in Figs. 16 and 17 , respectively.

heating-over a greater depth within the band. This is evident from the increase in buoyancy (i.e., larger $\theta_{v}$ anomalies) within the band along cross sections $\mathrm{B}-\mathrm{B}^{\prime}$ and $\mathrm{C}-\mathrm{C}^{\prime}$ (cf. Figs. $15 \mathrm{a}, \mathrm{c}, \mathrm{e})$, since buoyancy is proportional to $\theta_{v}-\overline{\theta_{v}}$ [Markowski and Richardson 2010, section 2c(3)]. This yields a stronger and more symmetric secondary circulation in cross section $\mathrm{C}-\mathrm{C}^{\prime}$, with clear convergence and divergence patterns (see vectors in Fig. 15e), similar to IOP2b (Bergmaier et al. 2017).

As in IOP2b, a second baroclinic LBF (hereinafter LBF2) develops along a smaller bulge in the southeastern shoreline of the lake (hereinafter southeastern bulge; see Fig. 1b) and extends inland to the northeast (Figs. 14c,e). Unlike IOP2b, LBF2 does not intersect the LLAP band but instead remains to its south (yellow arrow in Fig. 15e). This is the convergent boundary seen south of the LLAP band in Figs. 8c,f. LBF2 separates warmer lake-modified air to the northwest from cooler air over land that has undergone hardly any upstream modification (Figs. 14c,e). Multiple weak CLs also develop over Lake Ontario to the north and west of the primary CL. They appear to be associated with horizontal convective rolls (HCRs). MODIS imagery (not shown) indicates that cloud streets were present over the western half of the lake later that afternoon.
The simulated LLAP band in IOP9 is more transient than in IOP7; it is slowly migrating northward at 1430 UTC 9 January, shortly before it dissipates. Within relatively weak $\left(\sim 5 \mathrm{~m} \mathrm{~s}^{-1}\right)$ prevailing flow, the band has acquired the curvilinear orientation of Lake Ontario itself, crossing the shoreline at the southeastern bulge (Fig. 14b). Upstream, the primary CL driving the LLAP band has migrated northward over the lake, away from the southern bulge (Fig. 14d). This CL is still referred to as LBF1 since model output at earlier times (not shown) reveals that it is the same CL associated with LBF1 in IOP7. As this CL breaks off from the southern bulge and migrates toward the axis of maximum surface $\theta_{v}$ in the middle of the lake, the temperature gradient across it weakens considerably (Fig. 14f). The absence of a strong prevailing wind component allows for the secondary circulation to be more prominent, as observed (Fig. 9b) and as indicated by the vectors on either side of the band in Figs. 14b,d,f. The convergence appears to be at least partially driven by the opposing thermally forced flows from the northern and southern shorelines. Such thermally forced flows tend to be stronger and more organized under weaker synoptic winds, as has been observed elsewhere (e.g., Onton and Steenburgh 2001). 

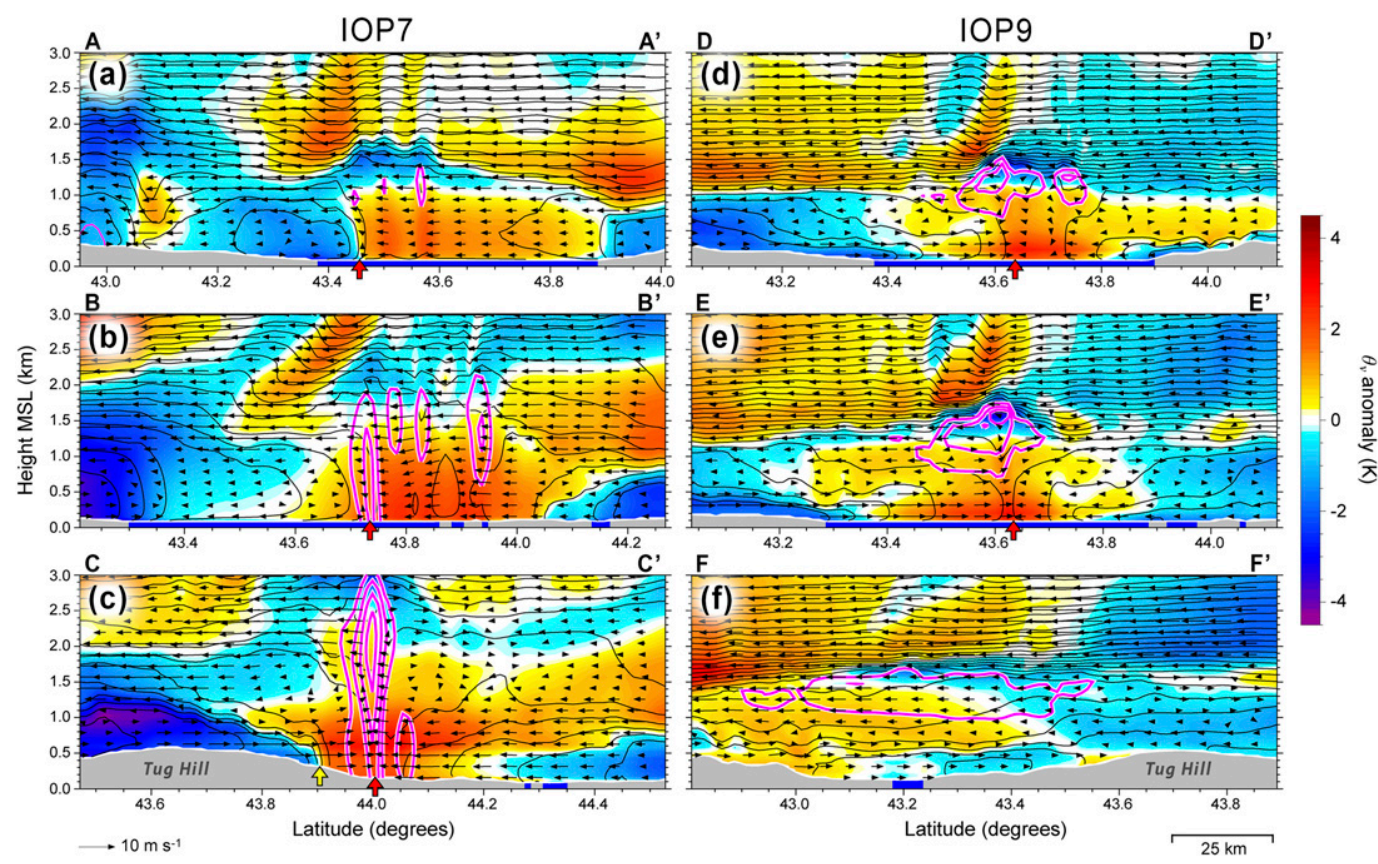

FIG. 15. WRF Model (1.33-km domain) $\theta_{v}$ anomalies (shaded), $\theta_{v}$ (black contours every $1 \mathrm{~K}$ ), and total condensed water (liquid + ice) mixing ratio (magenta contours every $0.25 \mathrm{~g} \mathrm{~kg}^{-1}$ ) for IOP7 at 1430 UTC 7 Jan along

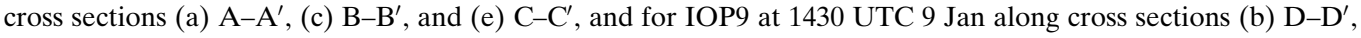
(d) $\mathrm{E}-\mathrm{E}^{\prime}$, and (f) $\mathrm{F}-\mathrm{F}^{\prime}$. The locations of the cross sections are shown in Fig. 14. The $\theta_{v}$ anomalies are given as a function of height, defined as $\theta_{v}(z)-\overline{\theta_{v}}(z)$. Wind vectors along the cross sections are plotted in each panel. The red and yellow arrows represent the surface position of the CL associated with LBF1 and LBF2, respectively.

As the band reaches the downwind shoreline near the southeastern bulge, it intersects the strong surface convergence and temperature gradient associated with LBF2 (Figs. 14d,f). Instead of extending inland like it does under stronger flow during IOP7, LBF2 remains locked to the eastern shoreline. In other words, the BL flow over the lake is blocked by the colder air east of LBF2. As a result, precipitation growth within the band ceases and the relatively weak LE precipitation becomes disorganized and gradually dissipates as it is carried onshore over the cold air (Figs. 4d, 14b, and 15f).

The model indicates that the band's surface convergence during IOP9 is strongly influenced by thermal forcing (i.e., surface heat fluxes) over the center of the lake, strengthened by internal processes such as buoyancy and latent heating. Significant latent heating does occur along the length of the band (see blue contours in Fig. 14f) as more precipitable water is available in the warmer but shallower BL compared to IOP7 (Table 1). Cross sections D-D' and $\mathrm{E}-\mathrm{E}^{\prime}$ indicate that the main updraft over the lake is very buoyant given the presence of overshooting tops penetrating into the stable layer above (Figs. 15b,d). Along the upwind cross section $\mathrm{D}-\mathrm{D}^{\prime}$, the band is initially positioned on the southern end of the lake's warm plume, over the leading edge of the stronger and slightly cooler southerly inflow associated with LBF1 (Fig. 15b). The band eventually becomes situated over the center of the warm plume by cross section E-E' (Fig. 15d), although cloud features and precipitation continue to extend southward over the cooler air (see Figs. 11d and 12d). Baroclinic forcing is more prominent a few hours earlier, when the band is farther south and closer to the southern shoreline (not shown). The simulated northward migration of the band is $\sim 3 \mathrm{~h}$ too fast. Thus, the transient nature of the simulated band may explain why it appears to be driven more by buoyancy at this time (1430 UTC), while the observed band, situated 10$20 \mathrm{~km}$ farther south, has characteristics more consistent with baroclinic forcing.

\section{b. Inland penetration of LE precipitation}

In terms of winter weather impacts, the most relevant difference in LLAP band structure is that the IOP7 band maintains its strength and penetrates far inland but the IOP9 band rapidly weakens onshore, blocked by stratified flow. Stronger flow during IOP7 allows the warmer lake-modified air and primary CL that accompany the band to remain unimpeded by the cooler air east of the lake as they move onshore (see Figs. 14a,c). Along the band (cross section $\mathrm{X}-\mathrm{X}^{\prime}$ ), this flow resides within a $\mathrm{BL}$ that deepens toward the downstream shore, aided by strong surface heating, appreciable cloud latent heating, and a relatively weak capping inversion (Fig. 16). The main updraft within the band reaches a depth of $2.5-3.0 \mathrm{~km}$ MSL near the eastern shoreline. The solenoidal circulation and associated updraft maintain their strength as the band moves inland. Over the lake, the decrease in equivalent potential temperature $\left(\theta_{e}\right)$ with height in the lowest $\sim 0.5 \mathrm{~km}$ (Fig. 16b) indicates appreciable potential instability within the band. 

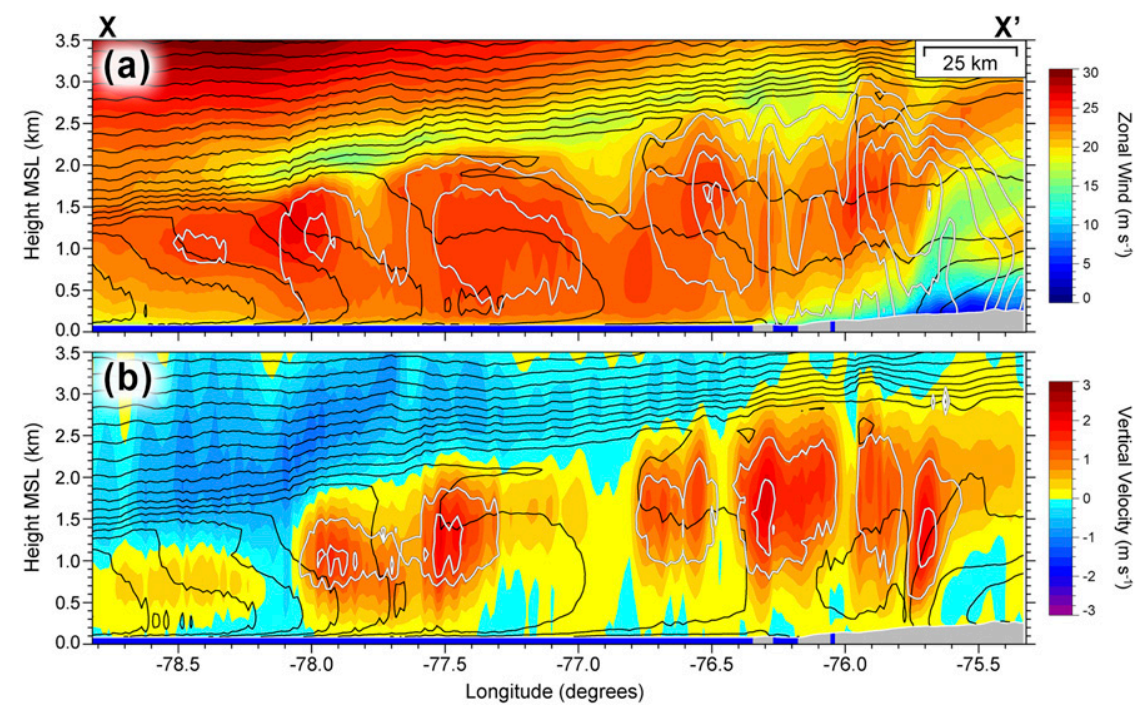

FIG. 16. IOP7 along-band analysis of WRF Model (1.33-km domain) cross section $X-X^{\prime}$ at 1430 UTC 7 Jan (see Fig. 14a for location). Shown are (a) zonal wind (shaded), $\theta_{v}$ (black contours every $1 \mathrm{~K}$ ), and total condensed water (liquid + ice) mixing ratio (white contours every $0.25 \mathrm{~g} \mathrm{~kg}^{-1}$ ), and (b) vertical velocity (shaded), $\theta_{e}$ (black contours every $1 \mathrm{~K}$ ), and latent heating rate (white contours every $4 \mathrm{~K} \mathrm{~h}^{-1}$ ). The ground and lake are shaded in gray and blue, respectively.

This explains the shallow convective towers seen by WCR (Figs. 6 and 7), convection that is assembled in a LLAP band by the convergent flow.

In IOP9, not only is the prevailing flow warmer and considerably weaker, but also the BL remains quite shallow beneath a much stronger capping inversion (Fig. 17a). The total condensed water (liquid + ice, including precipitation) mixing ratio contours in Fig. 17a indicate that not much precipitation was reaching the ground. Given the weaker flow and warmer overlying air mass (see Figs. 14c,d), surface sensible heat fluxes were not nearly as strong (Table 1), resulting in less surface heating along the band. The model does indicate considerable elevated latent heating within the updrafts due to the relatively warm and moist synoptic flow (Fig. 17b). However, this does not lead to appreciable deepening of the band, on account of the strong capping inversion. Upon reaching the eastern shoreline, the band intersects LBF2, which impedes the onshore progression of the low-level flow. This onshore flow is
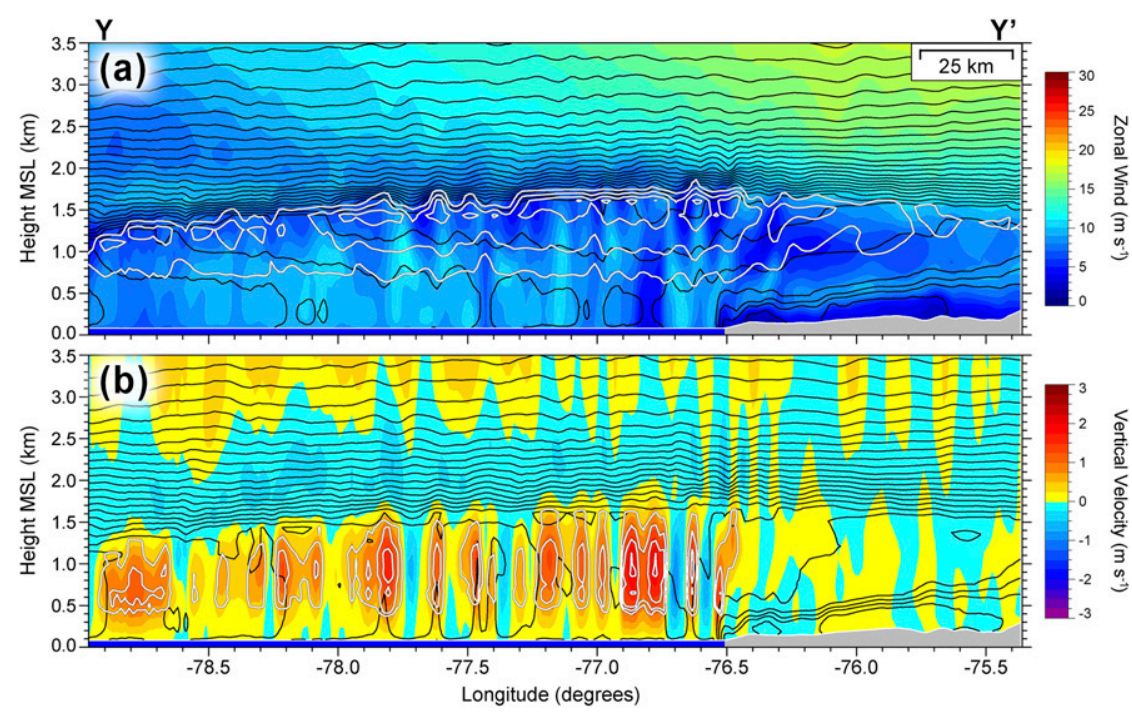

FIG. 17. As in Fig. 16, but for IOP9 along model cross section $\mathrm{Y}^{-\mathrm{Y}^{\prime}}$ at 1430 UTC 9 Jan (see Fig. $14 \mathrm{~b}$ for location). 

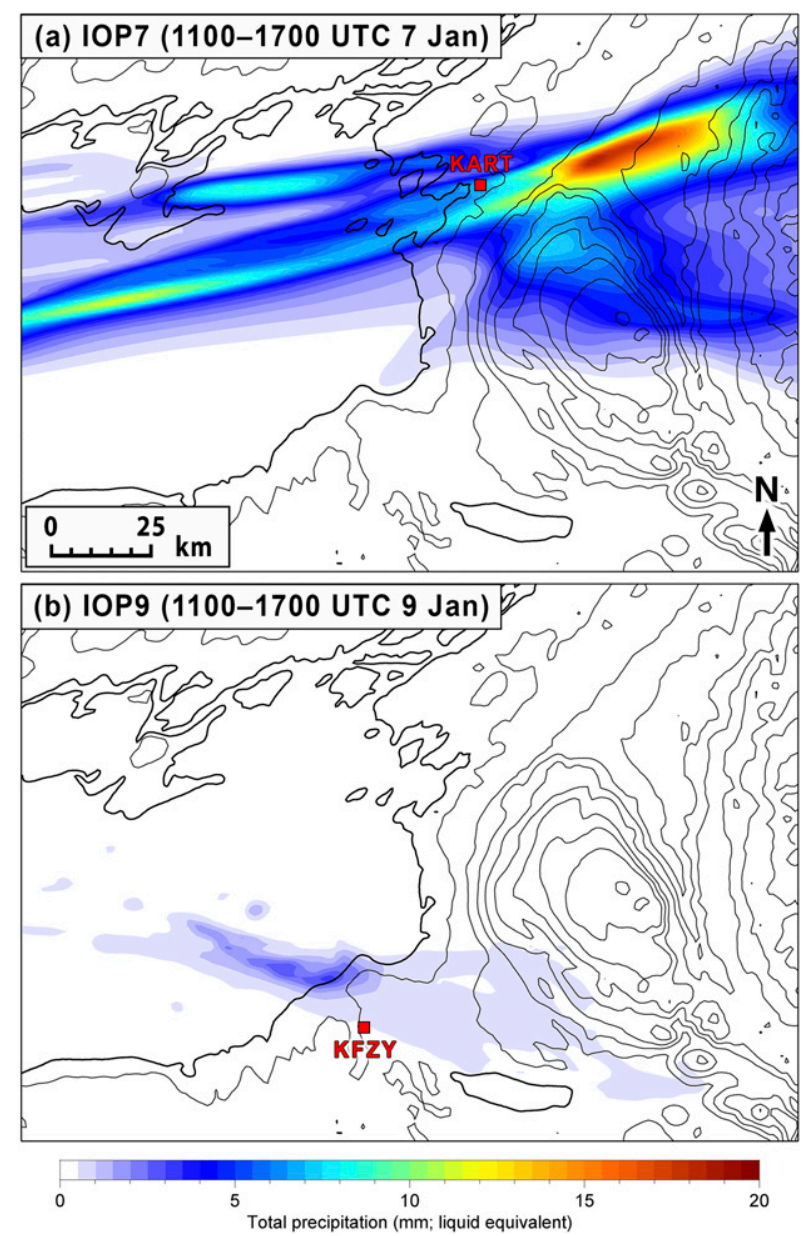

FIG. 18. WRF Model (1.33-km domain) 6-h total precipitation (1100-1700 UTC) for (a) IOP7 and (b) IOP9. The locations of ASOS stations KART and KFZY are shown. Terrain is contoured in black every $60 \mathrm{~m}$ MSL.

mostly blocked, with only a weak updraft along the leading edge of LBF2. Some moist lake-modified air does penetrate inland, wedged between the capping inversion above and the shallow, much cooler air mass below. Thus, the LLAP band disperses into a stratiform cloud deck over land, producing light snowfall that dissipates rapidly inland (see Figs. 4d and $15 f)$.

The differences in environmental conditions during the two IOPs lead to dramatically different inland precipitation amounts. The model produces up to $20 \mathrm{~mm}$ in liquid equivalent precipitation in $6 \mathrm{~h}$ far inland during IOP7, but only up to $\sim 3 \mathrm{~mm}$ near the shoreline during IOP9 (Fig. 18). This is consistent with the closest hourly gauge data. During IOP7, the KART ASOS station (see Fig. 18a for location) recorded $14.5 \mathrm{~mm}$ of precipitation over a 6-h period (Table 1), even though it was not situated right under the band. These gauge observations also likely suffered from undercatch given the strong winds (Rasmussen et al. 2012). During IOP9, a mere $0.5 \mathrm{~mm}$ of precipitation (Table 1) was recorded over a 6-h period by the KFZY ASOS station (see Fig. 18b for location). Daily Community Collaborative Rain,
Hail and Snow Network (CoCoRaHS; Reges et al. 2016) observations ${ }^{4}$ recorded east of the lake on the mornings of 8 and 10 January (not shown) indicate liquid equivalent precipitation amounts of up to $26.7 \mathrm{~mm}(66.0 \mathrm{~cm}$ of snowfall $)$ and $2.5 \mathrm{~mm}$ (8.1 cm of snowfall), respectively.

\section{Discussion}

In the above analyses, it is shown that the strength and direction of the prevailing BL flow impacts the development of surface CLs driven by temperature gradients, which in turn arise due to differences in surface heat fluxes experienced along flow trajectories. This supports recent work focusing on IOP2b that highlights the importance of shoreline geometry and differential surface heating in determining where these boundaries form, how they are oriented, and how they influence the development and downwind evolution of LLAP bands (Steenburgh and Campbell 2017; Bergmaier et al. 2017; Campbell and Steenburgh 2017).

Both IOP7 (studied herein) and IOP2b featured an "intense" LLAP band archetype, which forms under strong winds and strong surface heating. This type of LE circulation tends to produce heavy snowfall far inland in a narrow band. There was a minor difference between these two examples of the same archetype, related to the details of the prevailing flow. In IOP2b, LBF2 intersected the LLAP band, thereby enhancing LE precipitation over Tug Hill (Campbell and Steenburgh 2017). In IOP7, the prevailing flow had a slightly more southerly component, so LBF2 did not intersect with the LLAP band.

The weak, shallow band observed during IOP9, however, occurred in an environment of weaker flow, weaker surface heating, and stronger synoptic-scale subsidence. This represents the "weak" archetype along the LLAP band continuum, one that produces only light snowfall, closer to the shoreline. This is broadly consistent with other studies that found a positive relationship between wind speed and the intensity of LE precipitation (e.g., Veals et al. 2018). This study illustrates that LLAP bands can evolve across the spectrum between these archetypes during a cold air outbreak. During OWLeS, the intense archetype was observed more often, during at least four IOPs, while the weak archetype was observed only during IOP9. This does not imply that weak-precipitation LLAP bands are less common, even during the OWLeS campaign, which, by experimental design, focused on the more intense events.

In both archetypes, the band initially forms upstream along a baroclinic boundary (i.e., LBF1) along the southern bulge of Lake Ontario. The cooler, shallow air mass south of LBF1 resembles a density current that advances northward over the lake while also being advected eastward. Such a current has just a single solenoidal circulation with horizontal vorticity pointing eastward along the isotherms. Differential surface friction (Holroyd 1971; Steenburgh and Campbell 2017) initially contributes to the low-level convergence across this

\footnotetext{
${ }^{4}$ The CoCoRaHS measurements were typically made around 0700 LT (1200 UTC) each day by trained volunteers.
} 

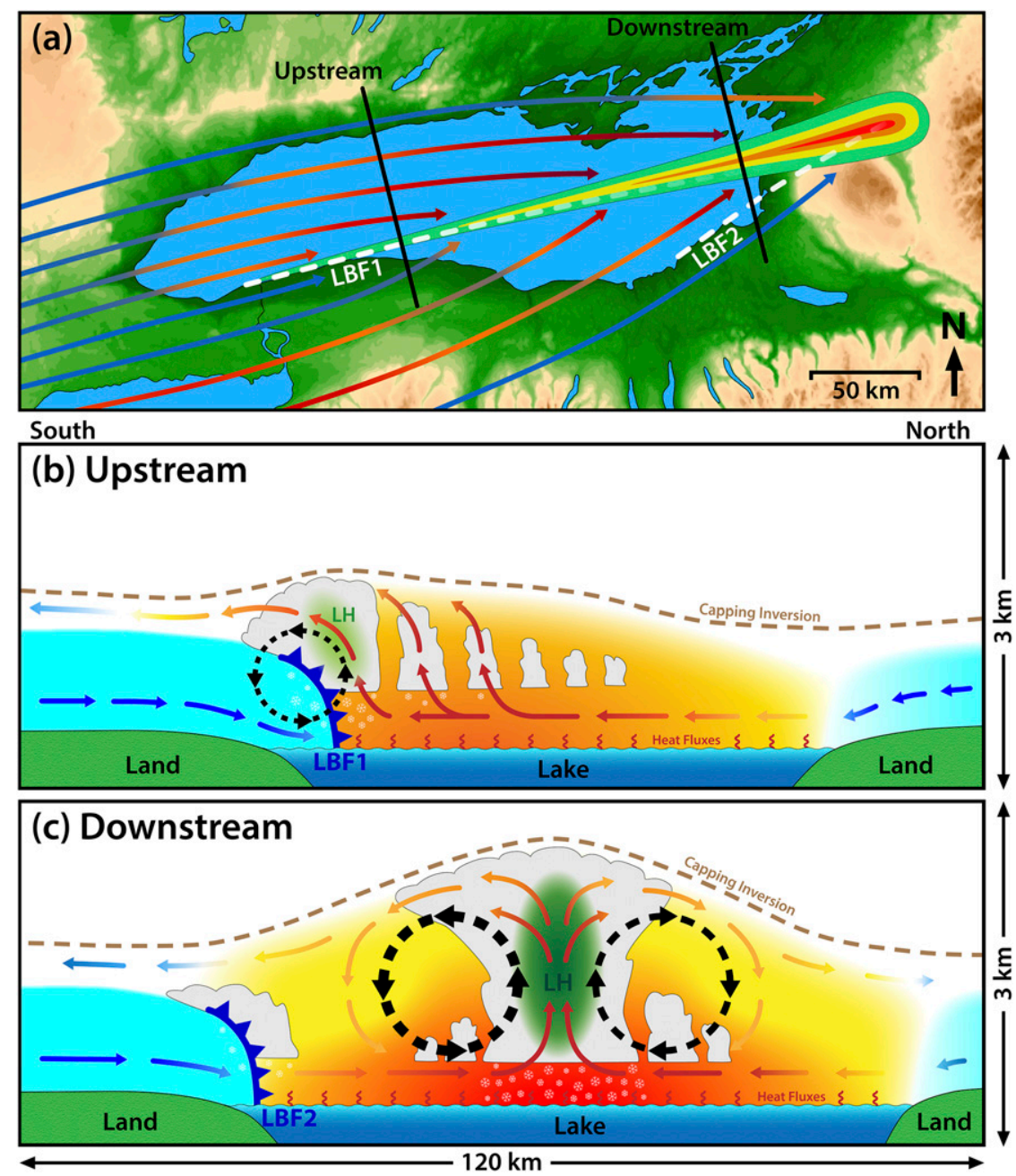

FIG. 19. Schematic summarizing the development and downstream evolution of a generic LLAP band over Lake Ontario. (a) The positions of the band (color filled by precipitation intensity), land-breeze fronts (white dashed lines with varying opacity reflecting the strength of low-level temperature gradient), and surface streamlines (color filled by temperature to indicate airmass modification). This panel has been partially adapted from Fig. 12 in Steenburgh and Campbell (2017). (b) Upstream and (c) downstream cross sections: the vectors represent the flow along the cross section (color filled by temperature) while the color-shaded backgrounds highlight the warmer lake-modified (from yellow to red) and cooler unmodified (light blue) air masses within the BL. The secondary circulation is represented by the black dashed circles/arrows (larger circle $=$ deeper circulation; thicker circle $=$ stronger circulation). Stronger LH within the band is indicated by darker shades of green.

boundary, especially during the intense archetype, because of stronger winds. Downstream over the lake, the cross-band baroclinity weakens and buoyancy (or thermal) forcing becomes more prominent, due to latent heating in cloud, mixing of heat from the surface layer, and cloud-top entrainment in a deepening convective BL. This allows the main updraft to deepen and the secondary circulation to become more symmetric, with two counterrotating vortices (Fig. 19). This transition is more pronounced during the intense archetype, because of stronger wind and higher surface fluxes. For both types, baroclinic forcing does not entirely disappear since the air mass south of the LLAP band remains slightly cooler than the air mass to the north, implying a stronger secondary circulation on the southern side of the band. In short, the current body of work based on OWLeS thus suggests that LLAP bands of any intensity do not generally develop as a result of converging land breezes over the center of Lake Ontario as shown in some textbooks (e.g., Fig. 9.19 in Lackmann 2011). Instead, $L L A P$ bands often form along a single $L B F$. This key finding is worth investigating over other large lakes, such as Lake Erie and Lake Michigan. For example, Lake Michigan has a large bulge along its eastern shoreline that may impact the upstream 
development of a single LBF under northerly to northnortheasterly BL flow. Snowbands sometimes form along a single LBF emanating south of this shoreline bulge when the BL flow over the lake has a considerable onshore (i.e., northwesterly) component (e.g., Hjelmfelt and Braham 1983; Braham 1983). However, because this flow opposes the LBF, the band usually remains situated close to the eastern shoreline. There are cases in which LLAP bands form over the center of Lake Michigan when the BL flow is more northerly (e.g., Passarelli and Braham 1981). It would be interesting to know if and how midlake LLAP bands over Lake Michigan (or Lake Erie) develop in a similar manner to the one observed over Lake Ontario in this study, not as a result of converging LBFs from opposing shorelines, but rather along a single LBF emanating from a bulge in the shoreline.

A well-organized and persistent secondary circulation was found in all seven LLAP bands observed by the WCR during OWLeS (not shown), suggesting that this thermally direct secondary circulation is likely a ubiquitous feature of LLAP bands. There is a positive feedback between the secondary circulation and the precipitation intensity with the LLAP band. The initial baroclinic circulation develops upstream across LBF1, where clouds and precipitation form within the convective updraft, releasing latent heat and increasing the updraft buoyancy. This acts to intensify the secondary circulation by strengthening and deepening the updraft itself, which thereby leads to an enhancement of the low-level convergence. The strengthening secondary circulation linearly concentrates the lake-induced convective cells farther downstream by suppressing updrafts in the region of compensating subsidence and by promoting convective growth within the band (thereby releasing more latent heat). Thus, the band deepens, precipitation intensifies, and the secondary circulation maintains its organization. This continues until the band moves inland and surface heat fluxes from the lake vanish. This circulation forms in both archetypes examined here. In the intense archetype (IOP7), the secondary circulation is maintained inland because of the stronger winds. In the weak archetype (IOP9), this circulation is largely contained over the lake and blocked from penetrating inland by LBF2 because of weaker BL winds, and because the circulation is shallower and more capped. However, the circulation within this archetype may in fact be stronger due to the longer advective time scale over the lake.

Model analysis indicates that the differences between IOP7 and IOP9 in terms of the band's inland penetration and the spatial distribution of LE precipitation east of Lake Ontario are likely influenced not just by 1) the strength of the prevailing BL flow, but also by 2) the magnitude of the surface heat fluxes (which depends not just on wind speed but also the lake-air temperature difference), 3) the strength and height of the BL capping inversion, and 4) the strength, depth, and orientation of LBF2 with respect to the band and its warmer onshore flow. Both points 2 and 4 are strongly influenced by point 1 , suggesting that the strength of the BL winds is the more important factor. However, the classification of the two IOPs into two archetypes controlled by wind speed only is an oversimplification. In IOP9, surface fluxes were reduced (Table 1) not just because of weaker winds, but also higher air temperature. Furthermore, the band's inland penetration was impeded not simply because of weaker winds, but also the rather low, strong capping inversion (Eipper et al. 2018) and the blocking presence of LBF2 along the shoreline. Eipper (2017, chapter 3) hypothesized that the greater inland penetration during IOP7 was also related to persistent along-band baroclinity east of the lake, which also relates to points 2 and 4 . Factors other than the four mentioned above, such as low-level wind shear, the upstream influence of other lakes, LE mode, and cold air advection (Villani et al. 2017; Veals et al. 2018; Eipper et al. 2018), may also have been important in differentiating the two LLAP bands but are beyond the scope of this study.

\section{Summary}

This study examines the 7-9 January 2014 persistent LLAP band over Lake Ontario using data collected during OWLeS, in particular airborne WCR single- and dual-Doppler observations from two UWKA flights during IOP7 and IOP9. These data are supplemented by well-validated, high-resolution $(1.33 \mathrm{~km})$ WRF Model output. The two cases represent two LLAP band archetypes: IOP7 illustrates an intense LLAP band that develops under strong winds and a very cold air mass; IOP9 illustrates a weak LLAP band that occurs under weak winds and a warmer air mass. The three main findings are as follows:

1) Both the intense and the weak LLAP bands were sustained by a well-organized mesoscale secondary circulation, composed of two counterrotating horizontal vortices positioned on either side of a narrow updraft, according to both WCR observations and model output.

2) Both the intense and the weak LLAP bands initially form along a baroclinic land-breeze front (LBF1) originating along the southern bulge in the lake shoreline. Thus, the secondary circulation initiates as a single vortex density current. The LLAP band then transitions into a less baroclinic environment as the convergence line moves downstream and the colder air south of LBF1 is modified over the lake. Buoyancy forcing, driven in part by latent heating within the band updraft, becomes more prominent, thus allowing the secondary circulation to become more symmetric (i.e., dual vortex) closer to the downwind shoreline.

3) Under strong winds, large surface heat fluxes, and weak capping aloft, the intense band (IOP7) grows to $2.5-3.0 \mathrm{~km}$ in depth and its secondary circulation remains strong and organized as the band moves onshore. This results in heavy snowfall and tremendous local accumulations well inland. Under weaker winds, smaller surface heat fluxes, and stronger capping aloft, the weak band (IOP9) remains shallow $(1.5-1.7 \mathrm{~km}$ deep) and is largely blocked by a stagnant cold air mass (LBF2) along the downwind shoreline. It produces only weak stratiform precipitation near the shoreline, with insignificant snow accumulation inland.

Acknowledgments. We thank all of the OWLeS participants, including the UWKA flight crew, who helped to collect the data used in this study. The DD code was written by Sam 
IOP7 - Leg 5
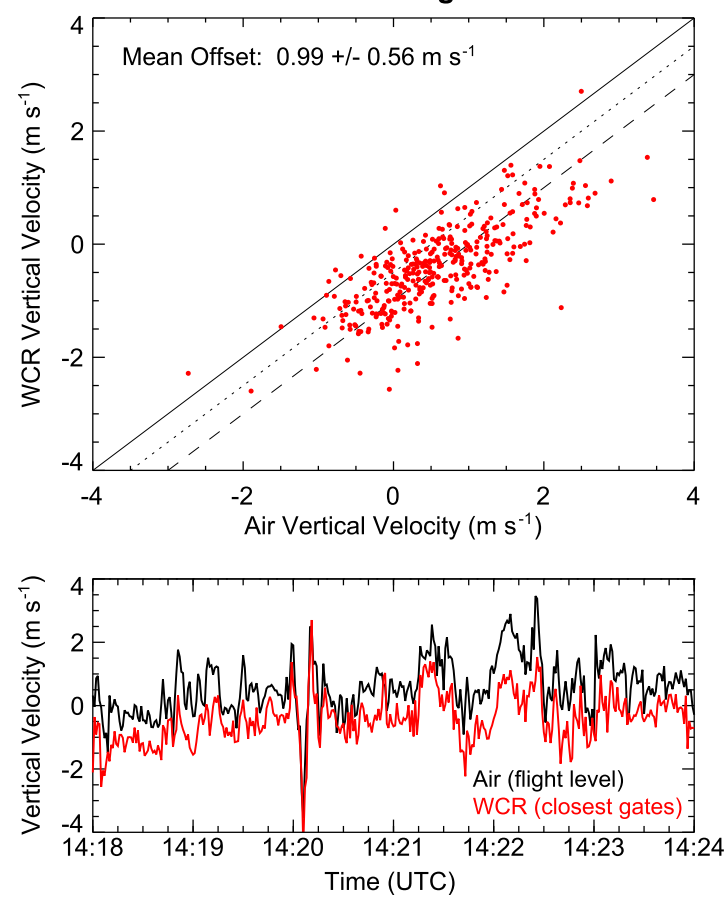

IOP9 - Leg 4
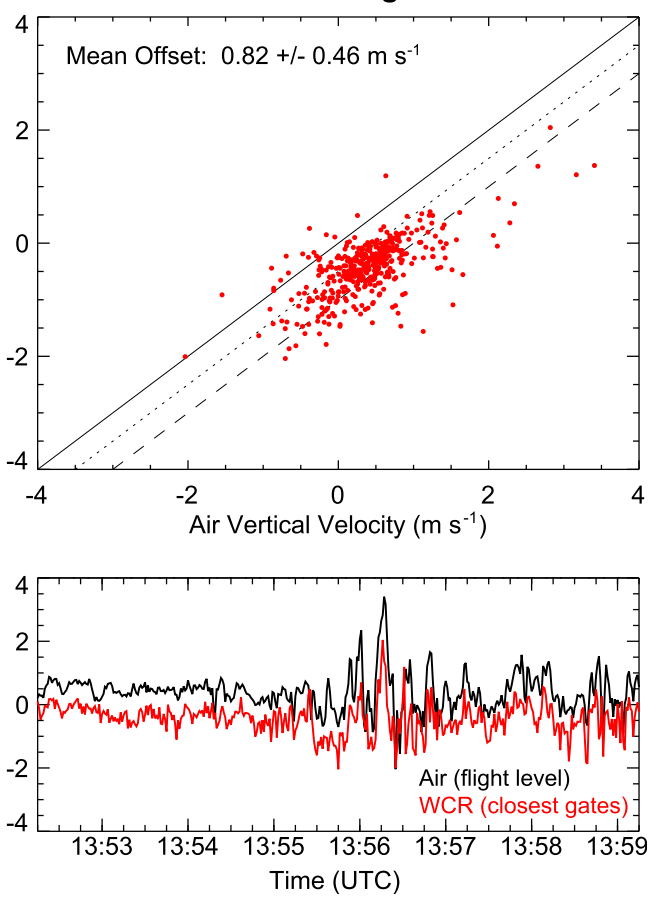

FIG. A1. Comparisons of air vertical velocity and WCR hydrometeor vertical velocity near flight level for two flight UWKA flight legs during (left) IOP7 and (right) IOP9. (top) The difference (i.e., offset) between the in situ air vertical velocity measurements at flight level and the average WCR hydrometeor vertical velocity from the two closest range gates above and below the aircraft. The dotted and dashed lines represent vertical velocity offsets of 0.5 and $1.0 \mathrm{~m} \mathrm{~s}^{-1}$, respectively. (bottom) The corresponding time series of these measurements.

Haimov and Rick Damiani. This work benefitted greatly from comments and suggestions offered by Jim Steenburgh, Zach Lebo, Jeff French, Tim Juliano, David Schultz, and several anonymous reviewers. Xia $\mathrm{Chu}$ assisted in configuring and running the WRF simulation. The simulation was conducted on the Cheyenne Supercomputer, which is supported by NCAR's Computational and Information Systems Laboratory and sponsored by the National Science Foundation. We acknowledge NCAR for the WRF software and for archiving and quality controlling many of the OWLeS datasets. The Center for Severe Weather Research provided the DOW7 radar data, level II NEXRAD data were obtained from the National Centers for Environmental Information, hourly ASOS observations were obtained from the University of Iowa Environmental Mesonet website, and GOES-13 visible satellite imagery was obtained from NOAA's Comprehensive Large Array-Data Stewardship System (CLASS). This work was funded by NSF Grants AGS-1258856 and DUE-1821566, as well as NASA Grant NNX15AI08H.

\section{APPENDIX A}

\section{Fall Speed Estimates and Uncertainties}

The fall speed estimates used in this study $\left(1.0 \mathrm{~m} \mathrm{~s}^{-1}\right.$ for 7 January and $0.75 \mathrm{~m} \mathrm{~s}^{-1}$ for 9 January) were based on the mean difference between the UWKA in situ air vertical velocity measurements obtained at flight level and the average of the WCR hydrometeor vertical velocity measurements from the closest available range gates above and below the aircraft (Fig. A1). Locally, appreciable variations in the reflectivityweighted fall speed, mainly due to riming, resulted in rather large uncertainties (i.e., standard deviations of $\sim 0.4-0.8 \mathrm{~m} \mathrm{~s}^{-1}$ ) in these differences during both flights. Such variations in fall speed are acceptable for the purpose of this study since the primary focus is ultimately on the integrated strength of the secondary circulation, which is dominated by the vertical wind shear.

In situ measurements at flight level (not shown) indicate that ice particle sizes varied significantly within the band on both days, typically ranging over $\sim 0.3-2.0 \mathrm{~mm}$ in diameter. Optical array probe imagery is used to examine the degree of hydrometeor riming. The maximum observed cloud liquid water content (LWC) at flight level was about $0.5 \mathrm{~g} \mathrm{~m}^{-3}$ during IOP7 and $1.0 \mathrm{~g} \mathrm{~m}^{-3}$ during IOP9, but average values were an order of magnitude lower. During IOP7, the band was mostly composed of smaller spherically shaped rimed particles with diameters of about $0.5 \mathrm{~mm}$ or less, although much larger $(>2 \mathrm{~mm})$ rimed aggregates were occasionally observed within the core of the band. A mixture of small, spherically shaped rimed particles and larger dendrites, columns, and aggregates are seen in the data from the IOP9 flight. Overall, there appears to have been less riming during IOP9 despite the larger observed LWC. Based on Mitchell (1996), typical fall speeds for these particle types and sizes likely ranged from 0.5 to $2.0 \mathrm{~m} \mathrm{~s}^{-1}$ during IOP7 and from 
0.5 to $1.0 \mathrm{~m} \mathrm{~s}^{-1}$ during IOP9, suggesting that the chosen mean fall speed estimates are reasonable.

\section{APPENDIX B}

\section{Dual-Doppler Band-Normal Horizontal Wind Retrieval}

Bergmaier et al. (2017) discuss how the along-track horizontal wind component $u_{\text {track }}$ is retrieved using DD synthesis of WCR observations. The DD synthesis yields a 3D wind vector at each point along the flight track, with two resolved components (vertical velocity and along-heading horizontal wind) determined by the down and down-forward WCR beams and an unresolved horizontal component that can be estimated by means of a user-specified wind profile. In this study, the wind profile was obtained from a proximity sounding (see section 2a). If there is a crosswind at flight level (as was the case in all of the flight legs in this study), the UWKA must point into the crosswind in order to maintain the desired ground track (i.e., the ground track and aircraft heading are thus not aligned). To retrieve $u_{\text {track }}$, the coordinate system of the 3D DD wind vector must be rotated so that one of the axes is oriented along the mean flight track. This of course increases the uncertainty in the DD analysis since $u_{\text {track }}$ thereby includes some of the unresolved wind estimate normal to the aircraft heading.

Since the secondary circulations examined in this study reside within the cross-band flow, it is ultimately only the horizontal component of the wind normal to the LLAP band $u_{\text {normal }}$ that is of interest. For IOP2b, the flight legs were very close to the LLAP band normal ( $<5^{\circ}$ off), in which case $u_{\text {track }}=$ $u_{\text {normal }}$ (Bergmaier et al. 2017). However, most of the flight legs in IOP7 and IOP9 were flown obliquely to the band, about $5^{\circ}-$ $10^{\circ}$ from normal (see section $4 \mathrm{a}$ ). This was enough to yield a noticeable southerly bias in $u_{\text {track }}$ in IOP7, given the strong prevailing west-southwesterly flow. The retrieval of $u_{\text {normal }}$ is similar to that of $u_{\text {track}}$, except that the coordinate system of the $3 \mathrm{D} D \mathrm{D}$ wind vector is instead rotated so that one of the axes is oriented normal to the mean orientation of the band (black line in Figs. 4a,c).

To account for uncertainty in the Doppler velocities due to weak WCR echoes, data points where the signal-to-noise ratio (SNR) was less than $0 \mathrm{~dB}$ have been removed. The SNR was larger than this for most of the data, yielding an uncertainty of less than $0.5 \mathrm{~m} \mathrm{~s}^{-1}$. Another source of uncertainty in this study is the sounding-based estimate of the unresolved horizontal wind component. A measure of this uncertainty can be deduced by comparing values of $u_{\text {normal }}$ that are obtained using wind profiles from soundings taken at different OWLeS sites around Lake Ontario. This was done with soundings taken from five locations during IOP7 at $\sim 1415$ UTC 7 January (Henderson Harbor, Oswego, North Redfield, and Sandy Creek, New York; and Darlington, Ontario, Canada) and from three locations during IOP9 at $\sim 1415$ UTC 9 January (from Oswego, Fair Haven Beach, and Stanley, New York). These locations are shown in Fig. 1b. During IOP7, the average and 90th-percentile RMS differences in $u_{\text {normal }}$ across all flight legs are 0.7 and $1.4 \mathrm{~m} \mathrm{~s}^{-1}$, respectively. During IOP9, these RMS differences are as small as 0.2 and $0.3 \mathrm{~m} \mathrm{~s}^{-1}$, respectively. The overall uncertainty in the retrieval of $u_{\text {normal }}$ is estimated to be on the order of $2 \mathrm{~m} \mathrm{~s}^{-1}$ or less on both days.

\section{REFERENCES}

Bergmaier, P. T., B. Geerts, L. S. Campbell, and W. J. Steenburgh, 2017: The OWLeS IOP2b lake-effect snowstorm: Dynamics of the secondary circulation. Mon. Wea. Rev., 145, 2437-2459, https://doi.org/10.1175/MWR-D-16-0462.1.

Braham, R. R., Jr., 1983: The Midwest snow storm of 8-11 December 1977. Mon. Wea. Rev., 111, 253-272, https://doi.org/10.1175/15200493(1983)111<0253:TMSSOD>2.0.CO;2.

Campbell, L. S., and W. J. Steenburgh, 2017: The OWLeS IOP2b lake-effect snowstorm: Mechanisms contributing to the Tug Hill precipitation maximum. Mon. Wea. Rev., 145, 2461-2478, https://doi.org/10.1175/MWR-D-16-0461.1.

$-\ldots,-$, P. G. Veals, T. W. Letcher, and J. R. Minder, 2016: Lake-effect mode and precipitation enhancement over the Tug Hill Plateau during OWLeS IOP2b. Mon. Wea. Rev., 144, 1729-1748, https://doi.org/10.1175/MWR-D15-0412.1.

Chen, F., and J. Dudhia, 2001: Coupling an advanced land surface-hydrology model with the Penn State-NCAR MM5 modeling system. Part II: Preliminary model validation. Mon. Wea. Rev., 129, 587-604, https://doi.org/10.1175/ 1520-0493(2001)129<0587:CAALSH >2.0.CO;2.

Chu, X., B. Geerts, L. Xue, and B. Pokharel, 2017: A case study of cloud radar observations and large-eddy simulations of a shallow stratiform orographic cloud, and the impact of glaciogenic seeding. J. Appl. Meteor. Climatol., 56, 1285-1304, https://doi.org/10.1175/JAMC-D-16-0364.1.

Damiani, R., and S. Haimov, 2006: A high-resolution dual-Doppler technique for fixed multiantenna airborne radar. IEEE Trans. Geosci. Remote Sens., 44, 3475-3489, https://doi.org/10.1109/ TGRS.2006.881745.

Eipper, D. T., 2017: Inland structure and penetration of Lake Ontario lake-effect dominant bands in baroclinic environments. Ph.D. dissertation, The Pennsylvania State University, $84 \mathrm{pp}$.

- G. S. Young, S. J. Greybush, S. Saslo, T. D. Sikora, and R. D. Clark, 2018: Predicting the inland penetration of long-lakeaxis parallel snowbands. Wea. Forecasting, 33, 1435-1451, https://doi.org/10.1175/WAF-D-18-0033.1.

Gerbush, M. R., D. A. R. Kristovich, and N. F. Laird, 2008: Mesoscale boundary layer and heat fluxes variations over pack ice-covered Lake Erie. J. Appl. Meteor. Climatol., 47, 668-682, https://doi.org/10.1175/2007JAMC1479.1.

Hjelmfelt, M. R., and R. R. Braham Jr., 1983: Numerical simulation of the airflow over Lake Michigan for a major lake-effect snow event. Mon. Wea. Rev., 111, 205-219, https://doi.org/10.1175/ 1520-0493(1983)111<0205:NSOTAO > 2.0.CO;2.

Holroyd, E. W., 1971: Lake-effect cloud bands as seen from weather satellites. J. Atmos. Sci., 28, 1165-1170, https://doi.org/10.1175/ 1520-0469(1971)028<1165:LECBAS > 2.0.CO;2.

Hong, S.-Y., Y. Noh, and J. Dudhia, 2006: A new vertical diffusion package with an explicit treatment of entrainment processes. Mon. Wea. Rev., 134, 2318-2341, https://doi.org/ 10.1175/MWR3199.1.

Houze, R. A., Jr., 2014: Cloud Dynamics. 2nd ed. International Geophysics Series, Vol. 53, Academic Press, 573 pp.

Iacono, M. J., J. S. Delamere, E. J. Mlawer, M. W. Shephard, S. A. Clough, and W. D. Collins, 2008: Radiative forcing by longlived greenhouse gases: Calculations with the AER radiative 
transfer models. J. Geophys. Res., 113, D13103, https://doi.org/ 10.1029/2008JD009944.

Jensen, A. A., P. T. Bergmaier, B. Geerts, H. Morrison, and L. S. Campbell, 2020: Sensitivity of convective cell dynamics and microphysics to model resolution for the OWLeS IOP2b lakeeffect snowband. Mon. Wea. Rev., 148, 3305-3328, https:// doi.org/10.1175/MWR-D-19-0320.1.

Jiménez, P. A., J. Dudhia, J. F. González-Rouco, J. Navarro, J. P. Montávez, and E. García-Bustamante, 2012: A revised scheme for the WRF surface layer formulation. Mon. Wea. Rev., 140, 898-918, https://doi.org/10.1175/MWR-D11-00056.1.

Kain, J. S., 2004: The Kain-Fritsch convective parameterization: An update. J. Appl. Meteor., 43, 170-181, https://doi.org/ 10.1175/1520-0450(2004)043<0170:TKCPAU > 2.0.CO;2.

__, and J. M. Fritsch, 1990: A one-dimensional entraining/ detraining plume model and its application in convective parameterization. J. Atmos. Sci., 47, 2784-2802, https://doi.org/ 10.1175/1520-0469(1990)047<2784:AODEPM>2.0.CO;2.

— models: The Kain-Fritsch scheme. The Representation of Cumulus Convection in Numerical Models, Meteor. Monogr., No. 24, Amer. Meteor. Soc., 165-170.

Kristovich, D. A. R., and Coauthors, 2017: The Ontario Winter Lake-effect Systems (OWLeS) Field Campaign: Scientific and educational adventures to further our knowledge and prediction of lake-effect storms. Bull. Amer. Meteor. Soc., 98, 315-332, https://doi.org/10.1175/ BAMS-D-15-00034.1.

Lackmann, G., 2011: Midlatitude Synoptic Meteorology: Dynamics, Analysis, and Forecasting. Amer. Meteor. Soc., 345 pp.

Leon, D., and G. Vali, 1998: Retrieval of three-dimensional particle velocity from airborne Doppler radar data. J. Atmos. Oceanic Technol., 15, 860-870, https://doi.org/10.1175/15200426(1998)015<0860:ROTDPV>2.0.CO;2.

,$- \ldots$, and M. Lothon, 2006: Dual-Doppler analysis in a single plane from an airborne platform. J. Atmos. Oceanic Technol., 23, 3-22, https://doi.org/10.1175/JTECH1820.1.

Markowski, P., and Y. Richardson, 2010: Mesoscale Meteorology in Midlatitudes. Wiley-Blackwell, $407 \mathrm{pp}$.

Matrosov, S. Y., 2007: Modeling backscatter properties of snowfall at millimeter wavelengths. J. Atmos. Sci., 64, 1727-1736, https://doi.org/10.1175/JAS3904.1.

Milbrandt, J. A., and M. K. Yau, 2005a: A multimoment bulk microphysics parameterization. Part I: Analysis of the role of the spectral shape parameter. J. Atmos. Sci., 62, 3051-3064, https://doi.org/10.1175/JAS3534.1.

$\longrightarrow$, and — 2005b: A multimoment bulk microphysics parameterization. Part II: A proposed three-moment closure and scheme description. J. Atmos. Sci., 62, 3065-3081, https:// doi.org/10.1175/JAS3535.1.

Minder, J. R., T. W. Letcher, L. S. Campbell, P. G. Veals, and W. J. Steenburgh, 2015: The evolution of lake-effect convection during landfall and orographic uplift as observed by profiling radars. Mon. Wea. Rev., 143, 4422-4442, https://doi.org/10.1175/ MWR-D-15-0117.1.

Mitchell, D. L., 1996: Use of mass- and area-dimensional power laws for determining precipitation particle terminal velocities. J. Atmos. Sci., 53, 1710-1723, https://doi.org/10.1175/15200469(1996)053<1710:UOMAAD > 2.0.CO;2.

Morrison, H., and J. A. Milbrandt, 2015: Parameterization of cloud microphysics based on the prediction of bulk ice particle properties. Part I: Scheme description and idealized tests.
J. Atmos. Sci., 72, 287-311, https://doi.org/10.1175/JAS-D-140065.1.

— G. Thompson, and V. Tatarskii, 2009: Impact of cloud microphysics on the development of trailing stratiform precipitation in a simulated squall line: Comparison of one- and two-moment schemes. Mon. Wea. Rev., 137, 991-1007, https://doi.org/ 10.1175/2008MWR2556.1.

Mulholland, J. P., J. Frame, S. W. Nesbitt, S. M. Steiger, K. A. Kosiba, and J. Wurman, 2017: Observations of misovortices within a long-lake-axis-parallel lake-effect snowband during the OWLeS Project. Mon. Wea. Rev., 145, 3265-3291, https:// doi.org/10.1175/MWR-D-16-0430.1.

Niziol, T. A., W. R. Snyder, and J. S. Waldstreicher, 1995: Winter weather forecasting throughout the eastern United States. Part IV: Lake effect snow. Wea. Forecasting, 10, 61-77, https://doi.org/ 10.1175/1520-0434(1995)010<0061:WWFTTE > 2.0.CO;2.

Onton, D. J., and W. J. Steenburgh, 2001: Diagnostic and sensitivity studies of the 7 December 1998 Great Salt Lake-effect snowstorm. Mon. Wea. Rev., 129, 1318-1338, https://doi.org/ 10.1175/1520-0493(2001)129<1318:DASSOT > 2.0.CO;2.

Passarelli, R. E., and R. R. Braham Jr., 1981: The role of the winter land breeze in the formation of Great Lakes snowstorms. Bull. Amer. Meteor. Soc., 62, 482-491, https://doi.org/10.1175/15200477(1981)062<0482:TROTWL>2.0.CO;2.

Peace, R. L., Jr., and R. B. Sykes Jr., 1966: Mesoscale study of a lake effect snow storm. Mon. Wea. Rev., 94, 495-507, https://doi.org/ 10.1175/1520-0493(1966)094<0495:MSOALE > 2.3.CO;2.

Rasmussen, R., and Coauthors, 2012: How well are we measuring snow: The NOAA/FAA/NCAR winter precipitation test bed. Bull. Amer. Meteor. Soc., 93, 811-829, https://doi.org/10.1175/ BAMS-D-11-00052.1.

Reges, H. W., N. Doesken, J. Turner, N. Newman, A. Bergantino, and Z. Schwalbe, 2016: CoCoRaHS: The evolution and accomplishments of a volunteer rain gauge network. Bull. Amer. Meteor. Soc., 97, 1831-1846, https://doi.org/10.1175/BAMS-D-14-00213.1.

Saslo, S., and S. J. Greybush, 2017: Prediction of lake-effect snow using convection-allowing ensemble forecasts and regional data assimilation. Wea. Forecasting, 32, 1727-1744, https:// doi.org/10.1175/WAF-D-16-0206.1.

Skamarock, W. C., and J. B. Klemp, 2008: A time-split non-hydrostatic atmospheric model for weather research and forecasting applications. J. Comput. Phys., 227, 3465-3485, https:// doi.org/10.1016/j.jcp.2007.01.037.

Steenburgh, W. J., and L. S. Campbell, 2017: The OWLeS IOP2b lake-effect snowstorm: Shoreline geometry and the mesoscale forcing of precipitation. Mon. Wea. Rev., 145, 2421-2436, https://doi.org/10.1175/MWR-D-16-0460.1.

Steiger, S. M., and Coauthors, 2013: Circulations, bounded weak echo regions, and horizontal vortices observed within longlake-axis-parallel-lake-effect storms by the Doppler on Wheels. Mon. Wea. Rev., 141, 2821-2840, https://doi.org/ 10.1175/MWR-D-12-00226.1.

, T. Kranz, and T. W. Letcher, 2018: Thunderstorm characteristics during the Ontario Winter Lake-effect Systems Project. J. Appl. Meteor. Climatol., 57, 853-874, https:// doi.org/10.1175/JAMC-D-17-0188.1.

Thompson, G., P. R. Field, R. M. Rasmussen, and W. D. Hall, 2008: Explicit forecasts of winter precipitation using an improved bulk microphysics scheme. Part II: Implementation of a new snow parameterization. Mon. Wea. Rev., 136, 5095-5115, https://doi.org/10.1175/2008MWR2387.1.

Veals, P. G., W. J. Steenburgh, and L. S. Campbell, 2018: Factors affecting the inland and orographic enhancement of lake-effect 
precipitation over the Tug Hill Plateau. Mon. Wea. Rev., 146, 1745-1762, https://doi.org/10.1175/MWR-D-17-0385.1.

Villani, J. P., M. L. Jurewicz, and K. Reinhold, 2017: Forecasting the inland extent of lake effect snow bands downwind of Lake Ontario. J. Oper. Meteor., 5, 53-70, https://doi.org/10.15191/ nwajom.2017.0505.

Wang, Z., and Coauthors, 2012: Single aircraft integration of remote sensing and in situ sampling for the study of cloud microphysics and dynamics. Bull. Amer. Meteor. Soc., 93, 653-668, https://doi.org/10.1175/BAMS-D-11-00044.1.
Welsh, D., B. Geerts, X. Jing, P. T. Bergmaier, J. R. Minder, W. J. Steenburgh, and L. S. Campbell, 2016: Understanding heavy lakeeffect snowfall: The vertical structure of radar reflectivity in a deep snowband over and downwind of Lake Ontario. Mon. Wea. Rev., 144, 4221-4244, https://doi.org/10.1175/MWR-D-16-0057.1.

Wurman, J., J. Straka, E. Rasmussen, M. Randall, and A. Zahrai, 1997: Design and deployment of a portable, pencil-beam, pulsed, 3-cm Doppler radar. J. Atmos. Oceanic Technol., 14, 1502-1512, https://doi.org/10.1175/1520-0426(1997)014<1502: DADOAP $>2.0 . \mathrm{CO} ; 2$. 